\title{
Jet Noise Prediction using Hybrid RANS/LES with Structured Overset Grids
}

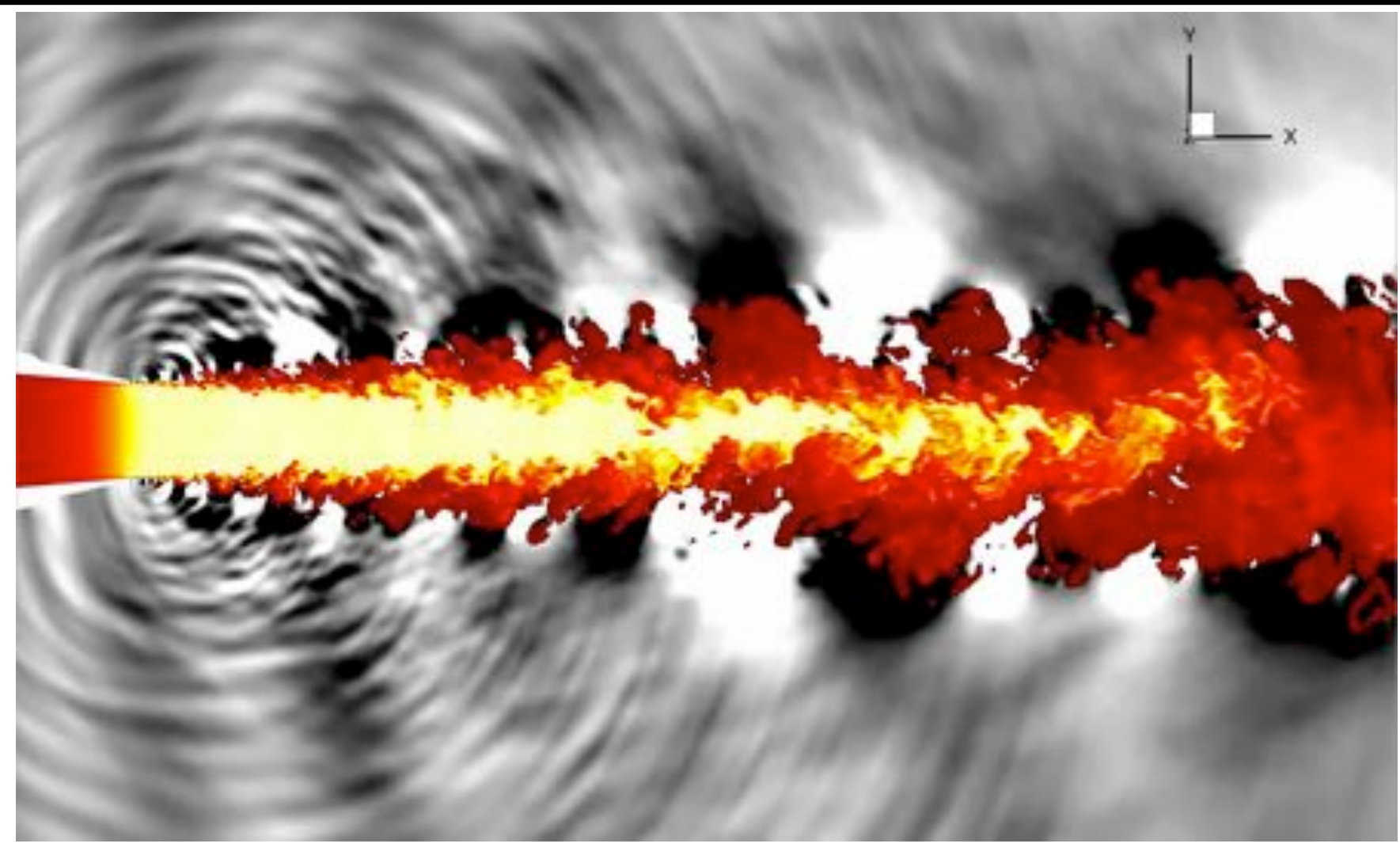

Jeffrey Housman

Computational Aerosciences Branch

NASA Ames Research Center

Co-Researchers: Gerrit-Daniel Stich, Cetin Kiris, and James Bridges

Advanced Modeling \& Simulation Seminar Series

NASA Ames Research Center, September 28, 2017

AIAA-2017-3213: J. Housman, G. Stich, C. Kiris, J. Bridges 


\section{Outline}

O Introduction

o Experimental Setup

- Computational Methodology

o Structured Overset Grid System

- Computational Results

- Near-Field Comparison

- Far-Field Comparison

o Summary

o Future Work 


\section{Introduction}

\section{Commercial Supersonic Transport (CST) ; Advanced Air Vehicle Program (AAVP)}

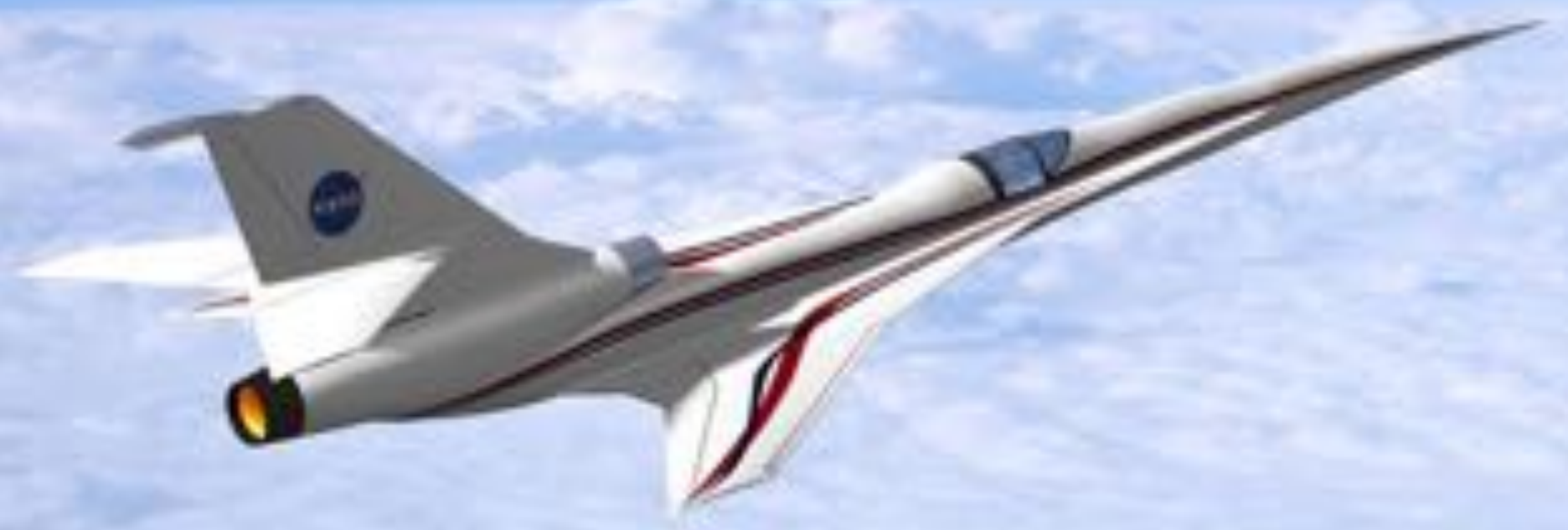

- NASA has initiated research activities toward quiet supersonic flight.

- Reduction of sonic boom ground signature.

- Constraints during takeoff and landing at subsonic speeds must be satisfied.

- Use computational aeroacoustics (CAA) tools to assess new designs.

- First part of a systematic validation effort in jet noise prediction capability for NASA Ames Launch Ascend and Vehicle Aerodynamics Code (LAVA). 


\section{Outline}

Experimental Setup

- Computational Methodology

- Structured Overset Grid

System

- Computational Results

- Near-Field Comparison

- Far-Field Comparison

- Summary

o Future Work

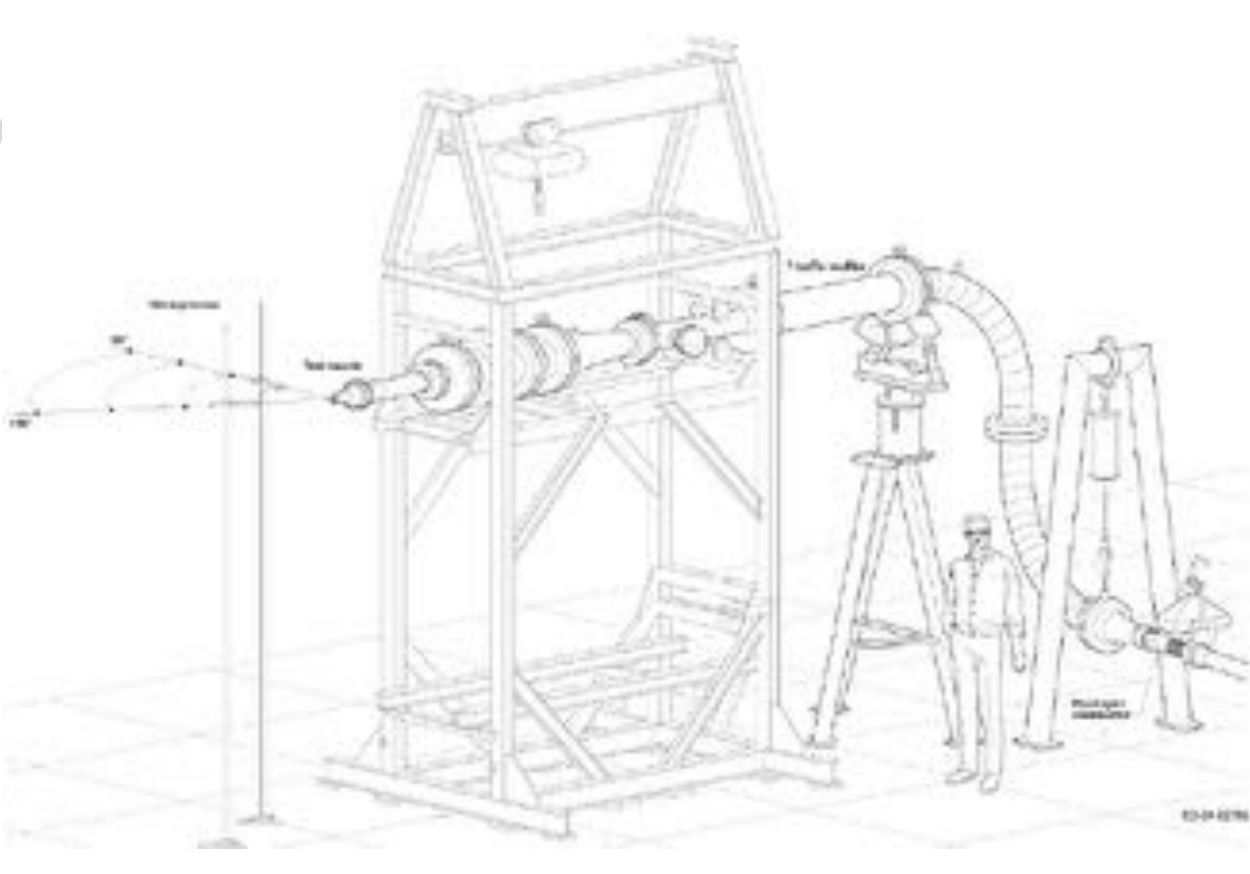




\section{Experimental Setup}

o Small Hot Jet Acoustic Rig (SHJAR), which is located in the Aeroacoustics Propulsion Lab (AAPL) at NASA Glenn Research Center

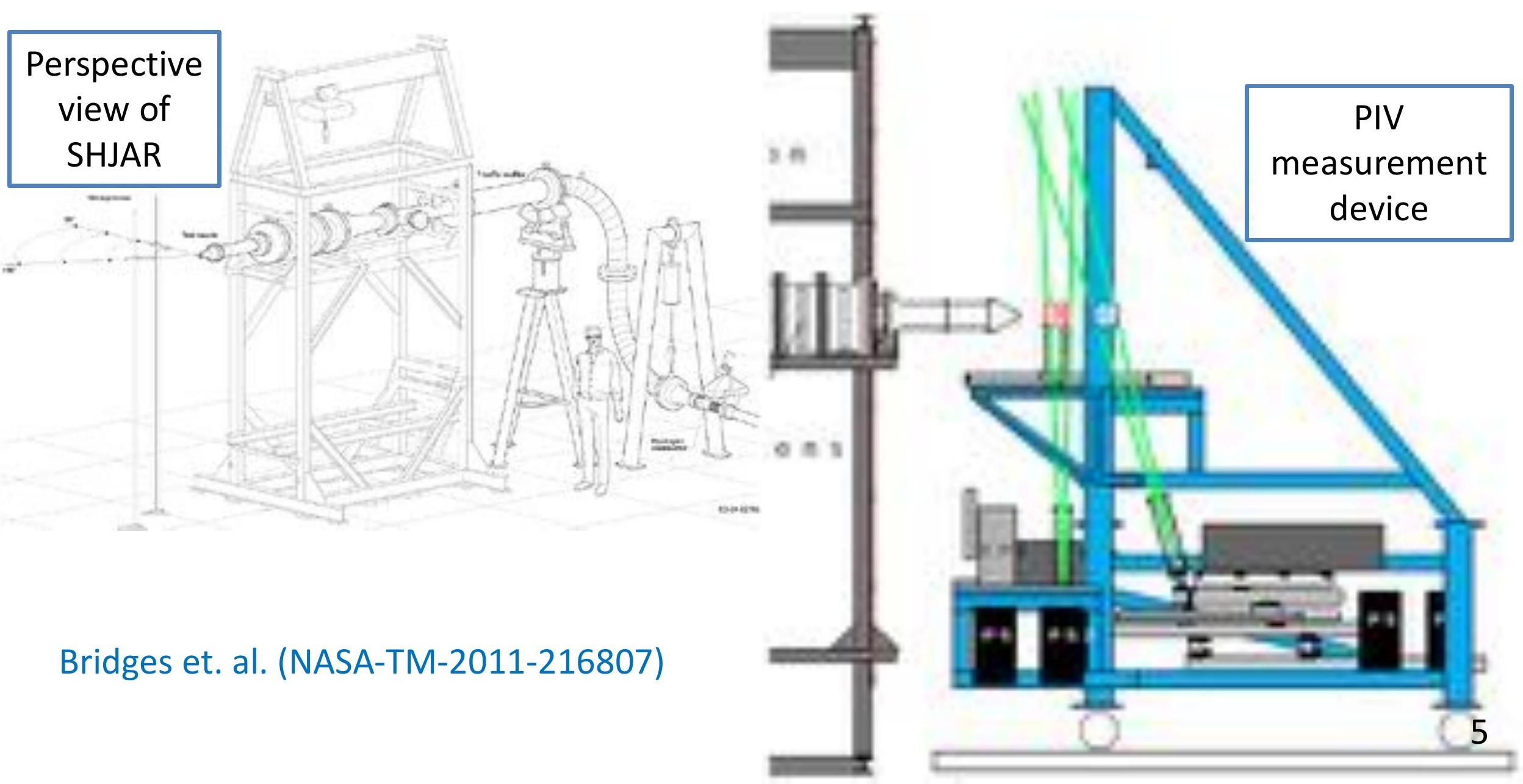




\title{
Outline
}

o Introduction

- Experimental Setup

○ Computational Methodology

\author{
$\xi_{2}$
}

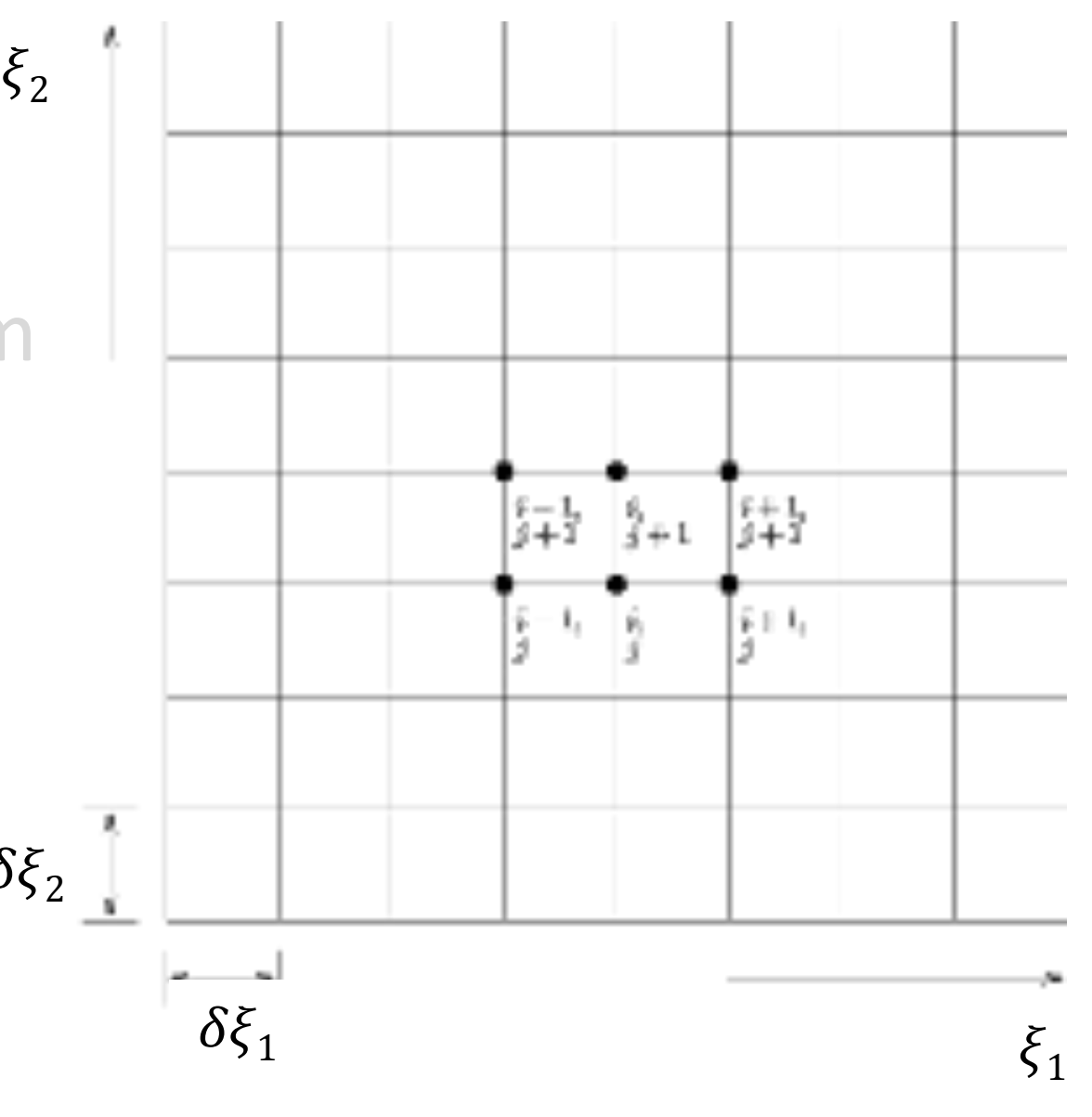




\section{Computational Methodology}

LAVA Framework (Kiris et al. Aerospace Science and Technology, Volume 55, 2016)

- Computational Fluid Dynamics Solvers

- Cartesian, Curvilinear, and Unstructured Grid Types

- Overset Grid and Immersed Boundary Methods

- Steady and Unsteady RANS (Reynolds-Averaged Navier-Stokes)

- Hybrid RANS/LES (Large Eddy Simulation), LES and LBM Capabilities

- Acoustic Solver

- Linear Helmholtz Scattering Code

- Permeable Surface Ffowcs Williams-Hawkings Propagation (FWH)
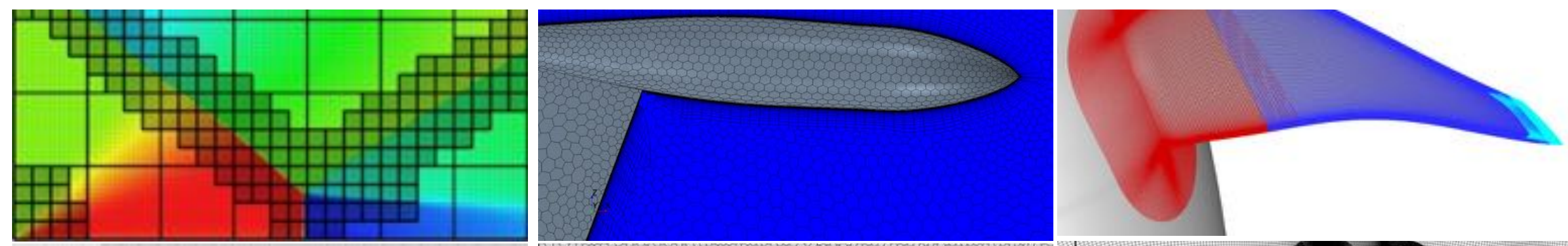

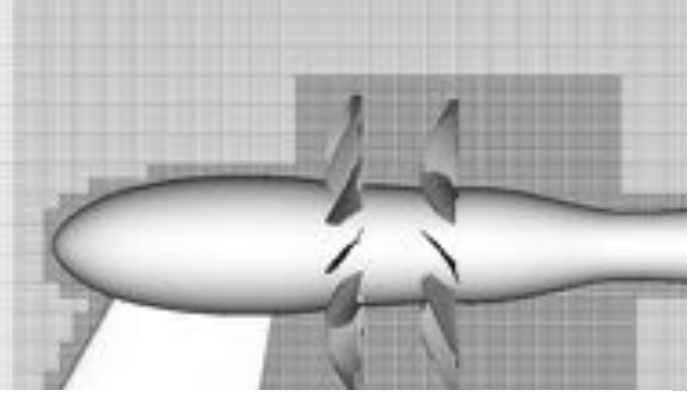

Cartesian Immersed Boundary

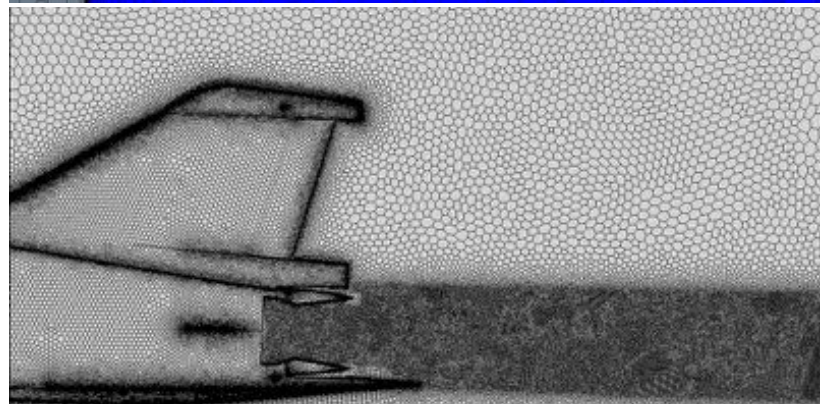

Unstructured Arbitrary Polyhedral

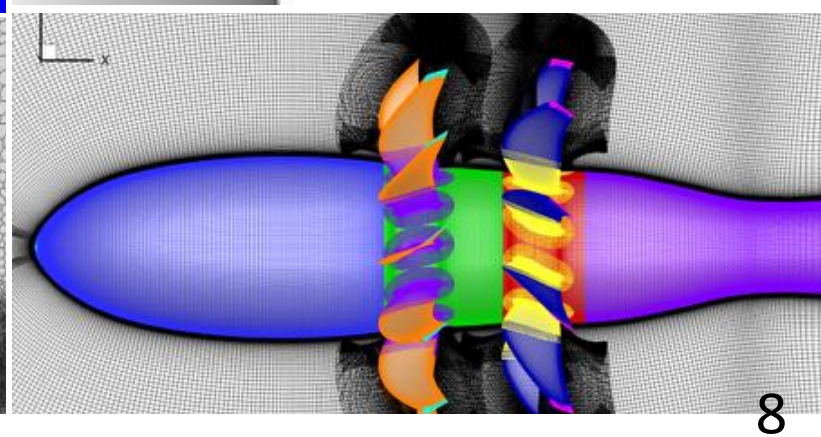

Overset Structured Curvilinear 


\section{Computational Methodology}

LAVA Framework (Kiris et al. Aerospace Science and Technology, Volume 55, 2016)

- Computational Fluid Dynamics Solvers

- Cartesian, Curvilinear, and Unstructured Grid Types

- Overset Grid and Immersed Boundary Methods

- Steady and Unsteady RANS (Reynolds-Averaged Navier-Stokes)

- Hybrid RANS/LES (Large Eddy Simulation), LES and LBM Capabilities

- Acoustic Solver

- Linear Helmholtz Scattering Code

- Permeable Surface Ffowcs Williams-Hawkings Propagation (FWH)

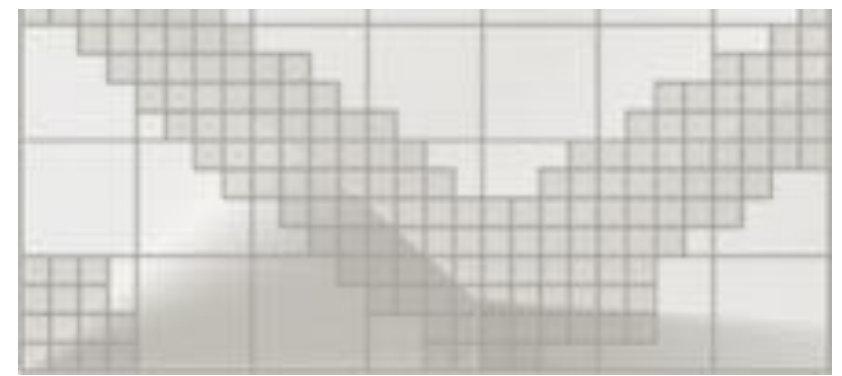

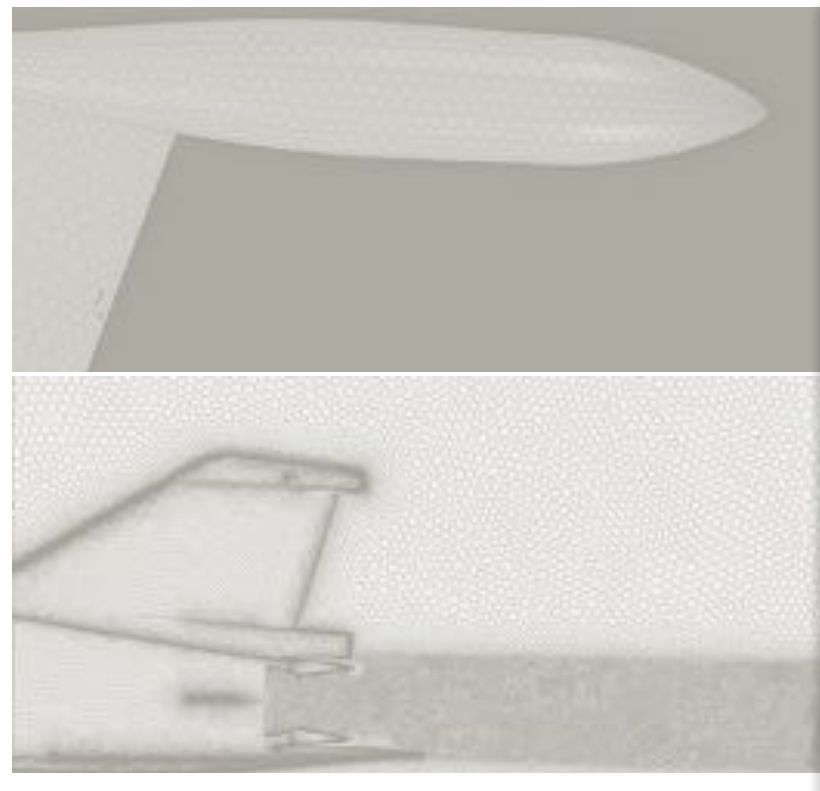

Unstructured Arbitrary Polyhedral

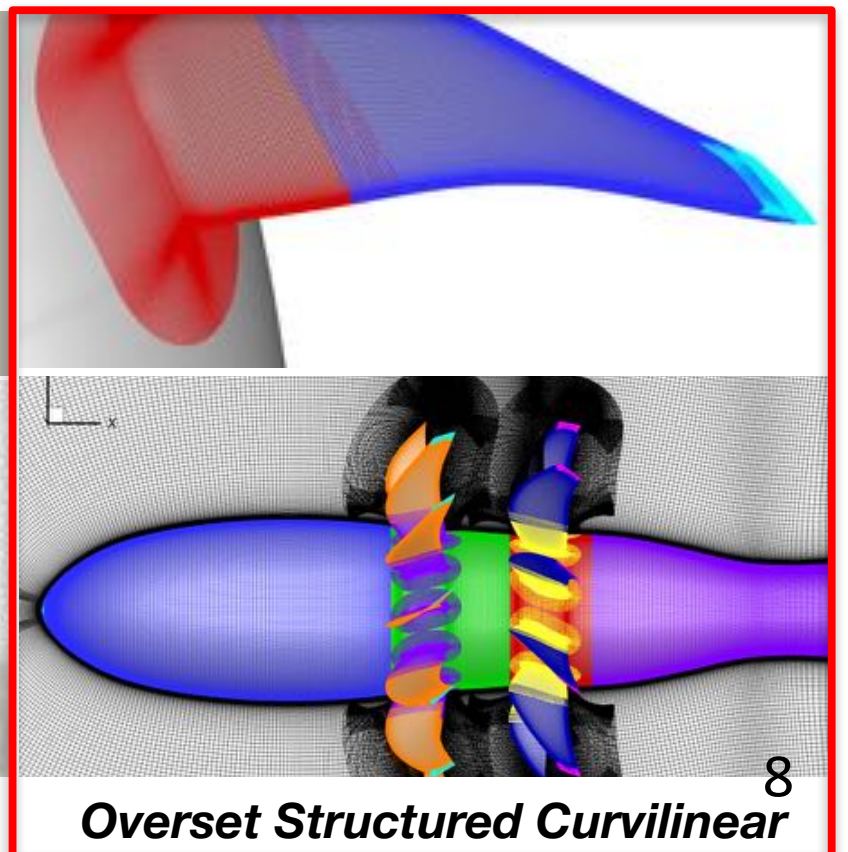




\section{Computational Methodology}

3-D Structured Curvilinear Overset Grid Solver

- Spalart-Allmaras turbulence model (baseline turbulence model)

Low-Dissipation Finite Difference Method (Housman et al. AIAA-2016-2963)

$\circ$ 6th-order Hybrid Weighted Compact Nonlinear Scheme (HWCNS)

O Numerical flux is a modified Roe scheme

$06^{\text {th }} / 5^{\text {th }}$-order blended central/upwind biased left and right state interpolation

$\circ 2^{\text {nd }}$-order accurate differencing used for time discretization

Hybrid RANS/LES Models

○ Delayed Detached Eddy Simulation (DDES) model with modified length scale (Housman et al. AlAA-2017-0640)

- Zonal RANS-NLES (numerical LES) with user selected zones of URANS, NLES, and wall-distance based hybrid RANS-NLES (see paper for details)

Synthetic Eddy Method

Coupling Methodology between RANS and LES to introduce realistic turbulent eddies (Jarrin et al. Int. Journal of Heat and Fluid Flow 30 ) 


\section{Computational Methodology}

O When transitioning from RANS to LES in wall-bounded flows it is necessary to insert meaningful three-dimensional content at the interface

o The synthetic eddy method (SEM) is one approach which adds eddies such that first and second order turbulent statistics can be recovered. (approx. from the RANS solution with Bradshaw hypothesis)

Jet Case SP 7

$$
\begin{aligned}
& \Delta x S_{E M}=x e_{x i t}-x S E_{M} \\
& 54 \delta<\Delta x S E_{M}<55 \delta
\end{aligned}
$$




\section{Computational Methodology}

O Unsteady RANS until jet is fully developed and

URANS

$\Delta t=1 \cdot 10^{-4}[\mathrm{~s}] ; 0.4[\mathrm{~s}]$

initialize Hybrid RANS/LES

$\Delta t=1 \cdot 10^{-6}[\mathrm{~s}]$

time steps $>30000$

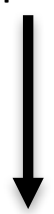

final Hybrid RANS/LES

$\Delta t=1 \cdot 10^{-6}[\mathrm{~s}]$

$\mathrm{St}_{\text {max }}=16.25, \mathrm{St}_{\text {min }}=0.008$

$T_{\text {conv }} \approx 205$ eddy viscosity maximum has plateaued

- Restart simulation with Hybrid RANS/LES Models until transient behavior washed out

- Ignore transients which are taken at first $\mathbf{3 0 0 0 0}$ time steps and restart simulation

- Record Volume data at $100 \mathrm{kHz}$ sampling frequency for greater than 0.02 seconds (approx. 205 convective time units)

\begin{tabular}{|l|c|c|c|}
\hline & baseline & coarse & refined \\
\hline Processors & 1392 (has) & 260 (ivy) & 960 (has) \\
\hline Wall-Clock Time [days] & \multicolumn{3}{|c|}{12.5} \\
\hline Sub-iterations & \multicolumn{3}{|c|}{5} \\
\hline Convergence & $2-4$ orders every sub-iteration \\
\hline Number Eddies (SEM) & - & 5000 & 5000 \\
\hline
\end{tabular}




\section{Outline}

Introduction

- Experimental Setup

- Computational Methodology

o Structured Overset Grid System

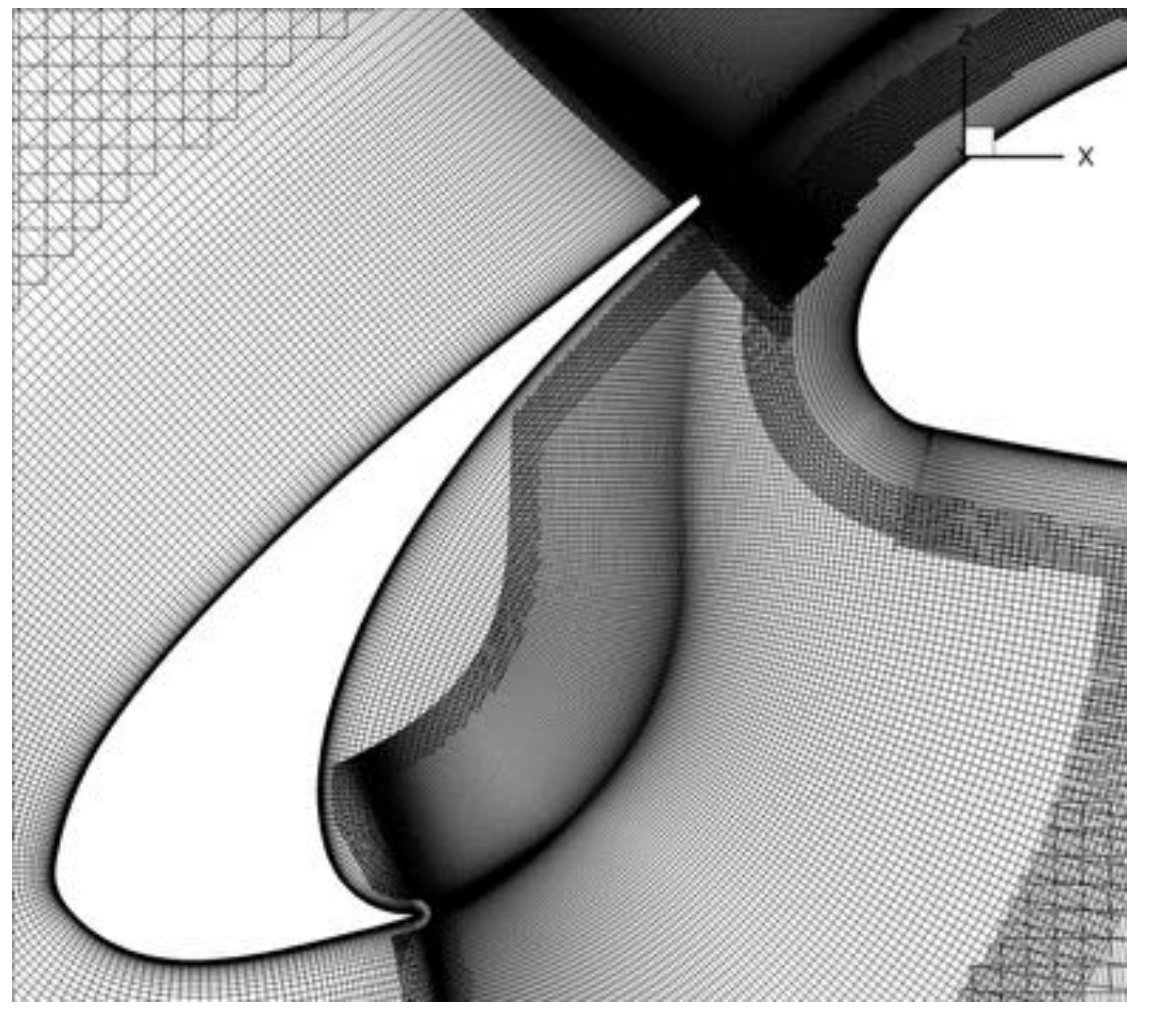

Near-Field Comparison

Far-Field Comparison

- Summary

o Future Work 


\section{Structured Overset Grid System}

- Baseline (256 M)

- Coarse ( $28 \mathrm{M})$

o Refined (106 M)

- Seven point overlap

- No orphan points

- Minimum stencil quality 0.9

- Baseline follows Bogey et. al (AIAA-2016-0261) 


\section{Structured Overset Grid System}

- Circumferential refinement in axial and radial direction Bres et. al. (AIAA-2015-2535) 


\section{Structured Overset Grid System}

circumferential refinement

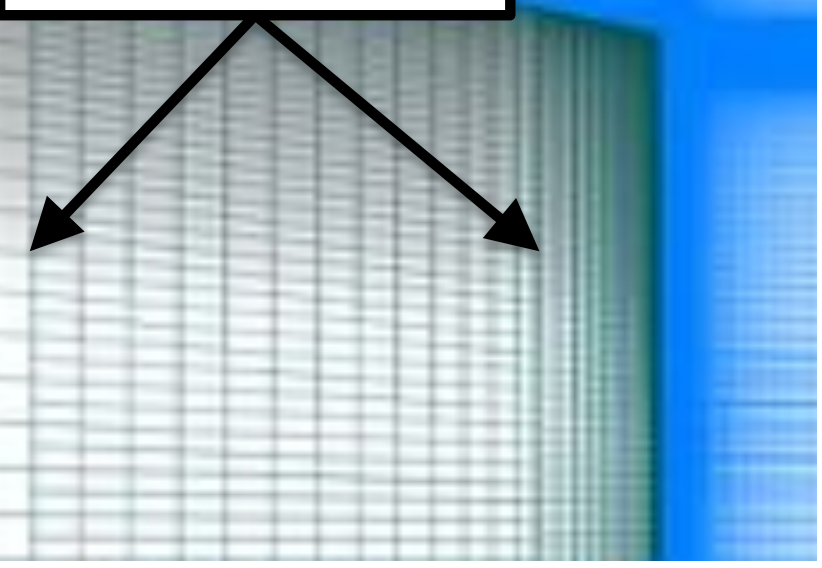

- Circumferential refinement in axial and radial direction Bres et. al. (AIAA-2015-2535) 


\section{Structured Overset Grid System}

circumferential refinement

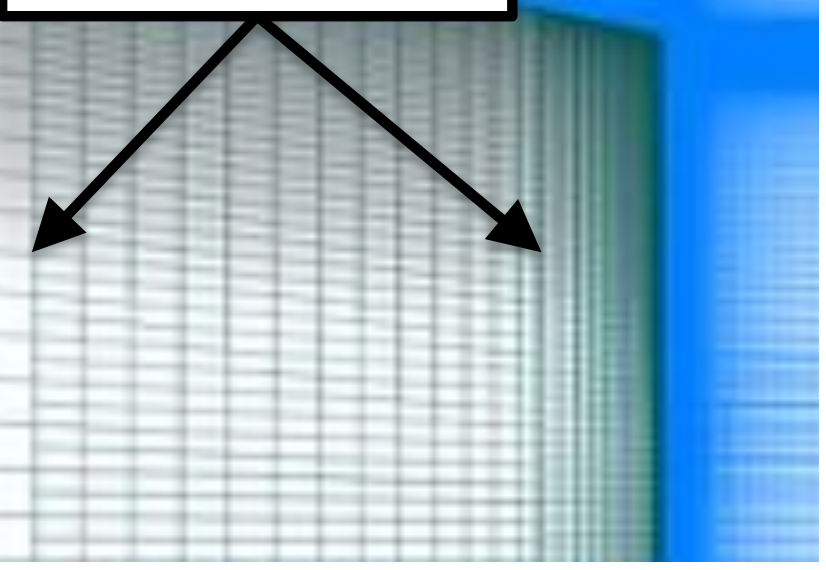

- Circumferential refinement in axial and radial direction Bres et. al. (AIAA-2015-2535)
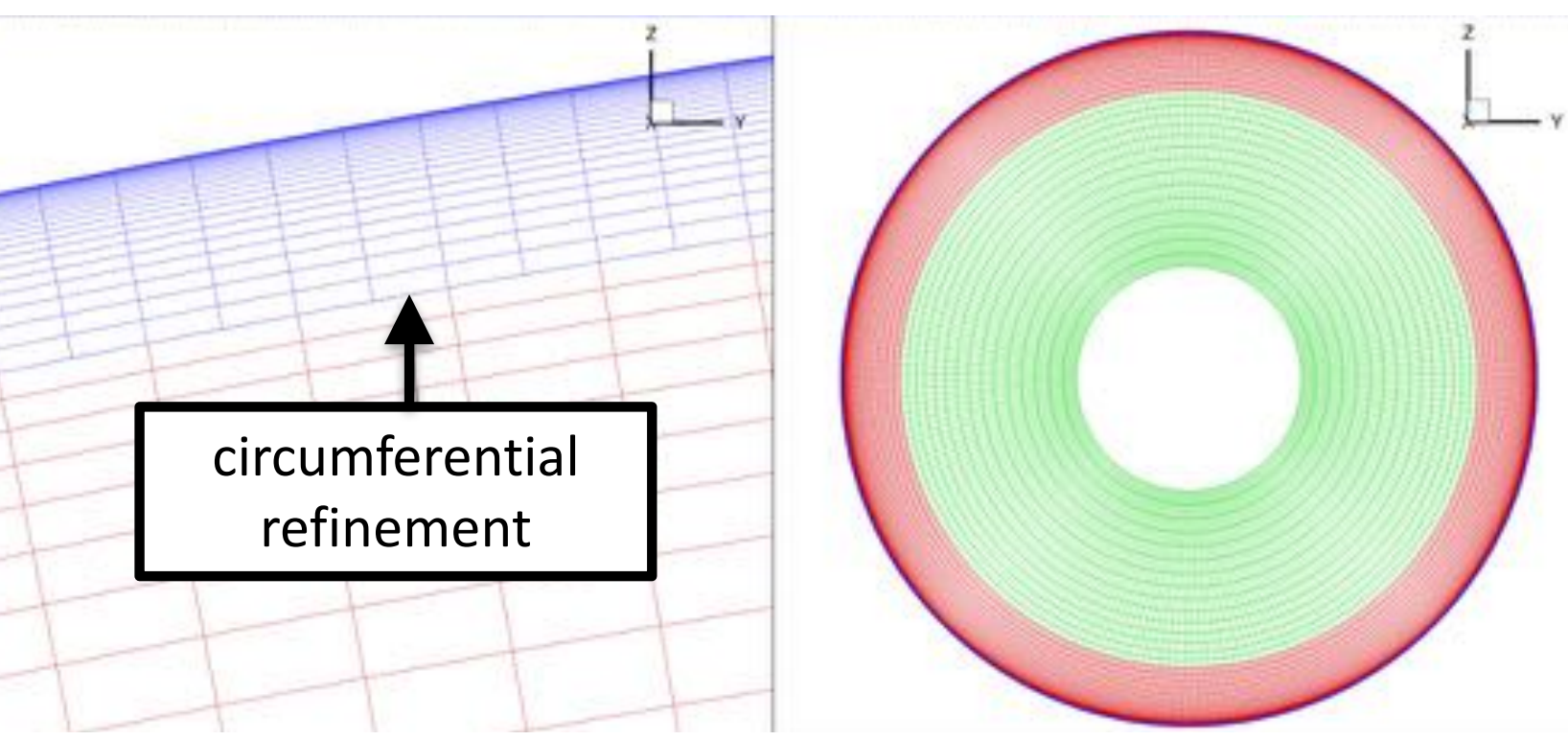

coarse | refined

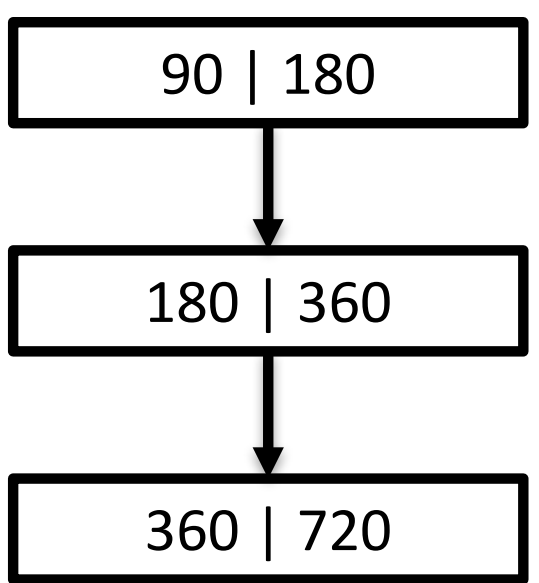

baseline 360 


\section{Structured Overset Grid System}

NASA axial/radial AR

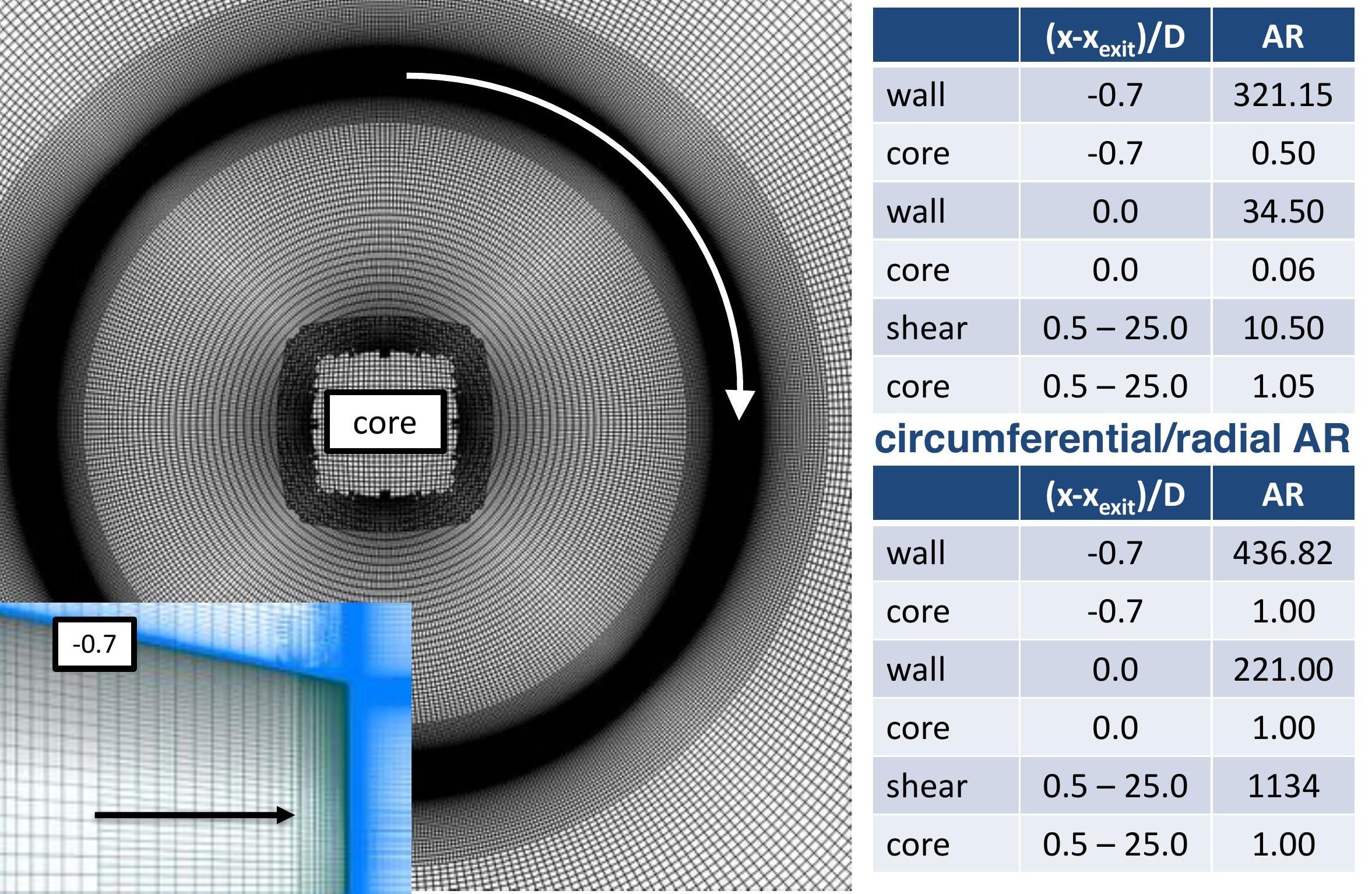




\section{Structured Overset Grid System}
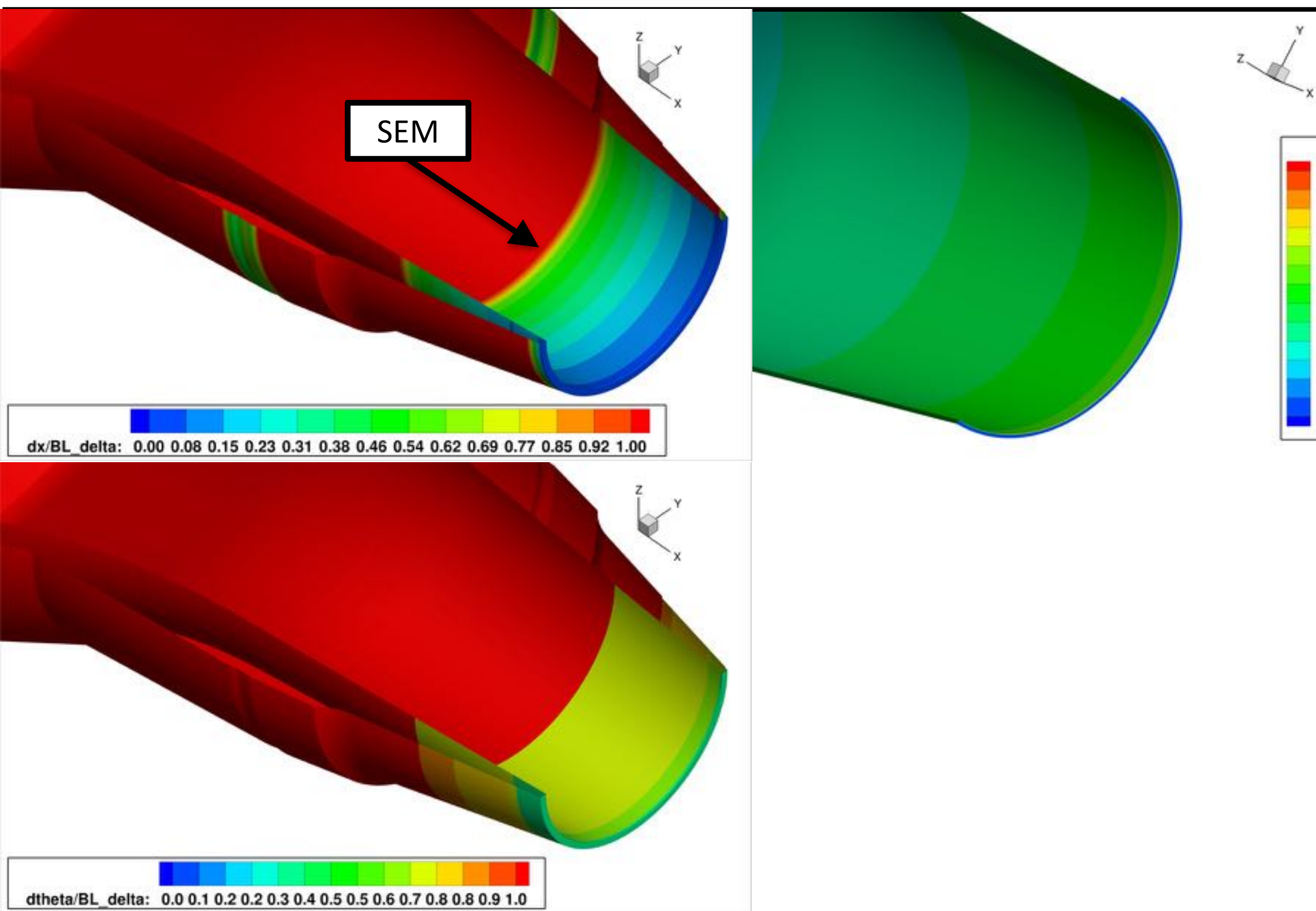


\section{Outline}

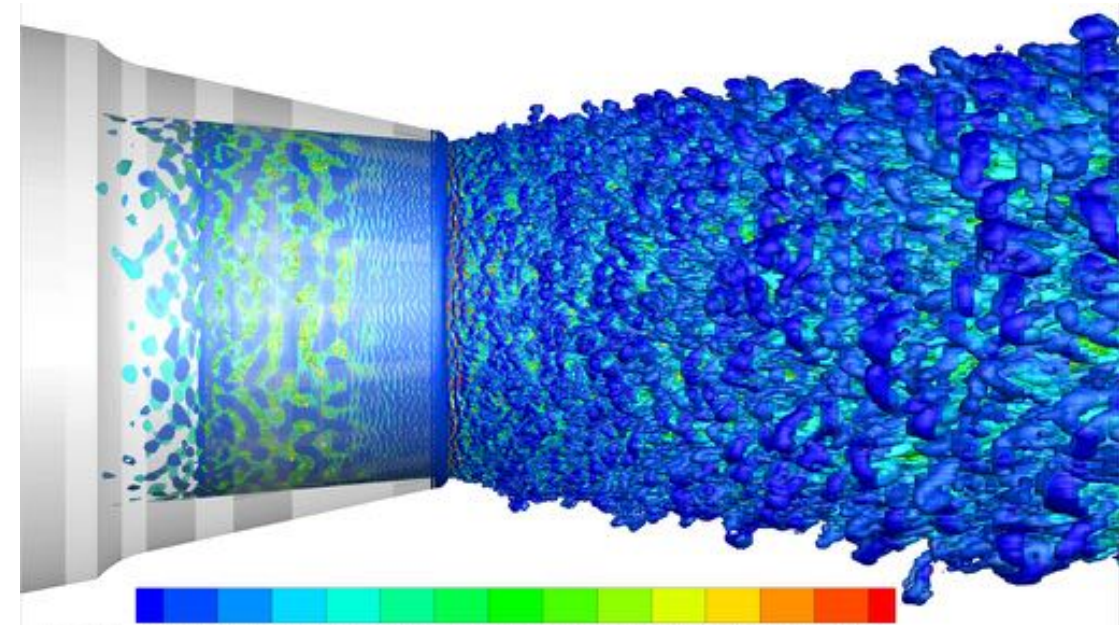

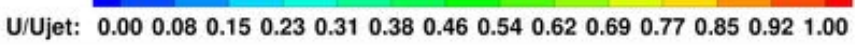

- Near-Field Comparison

- Far-Field Comparison

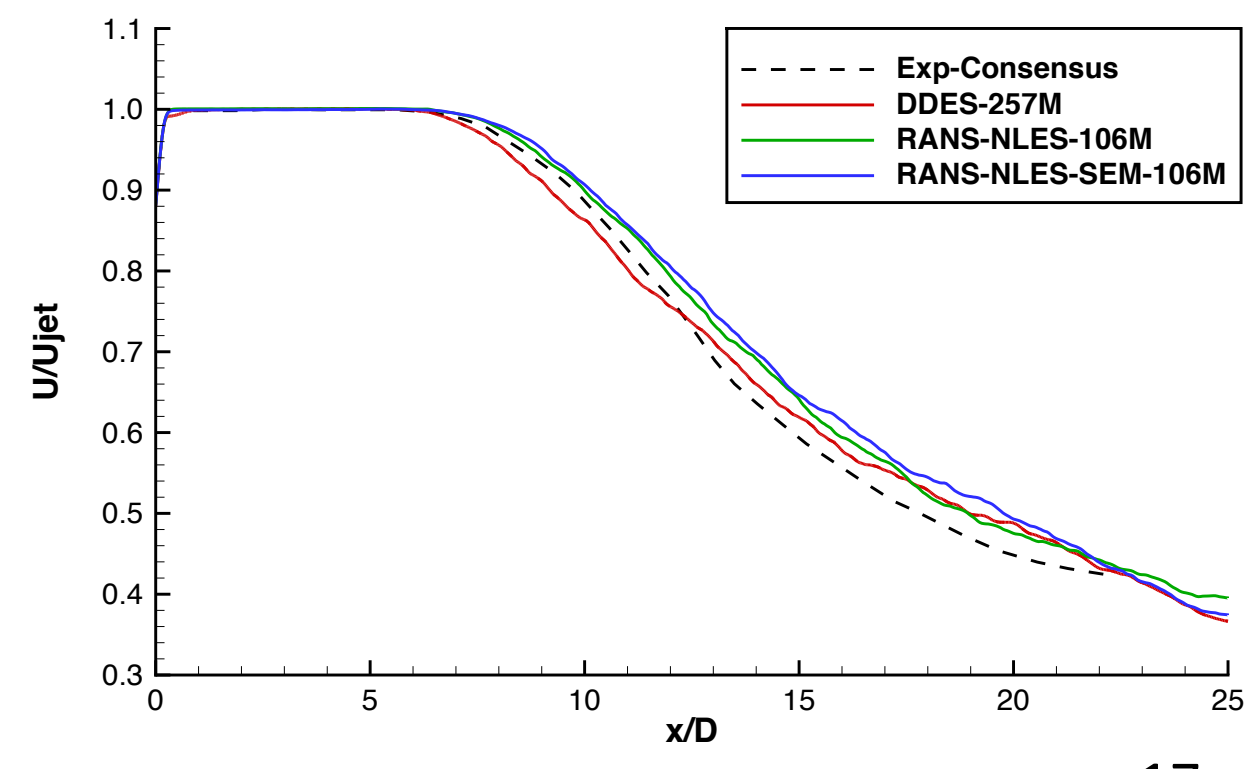




\section{Computational Results}

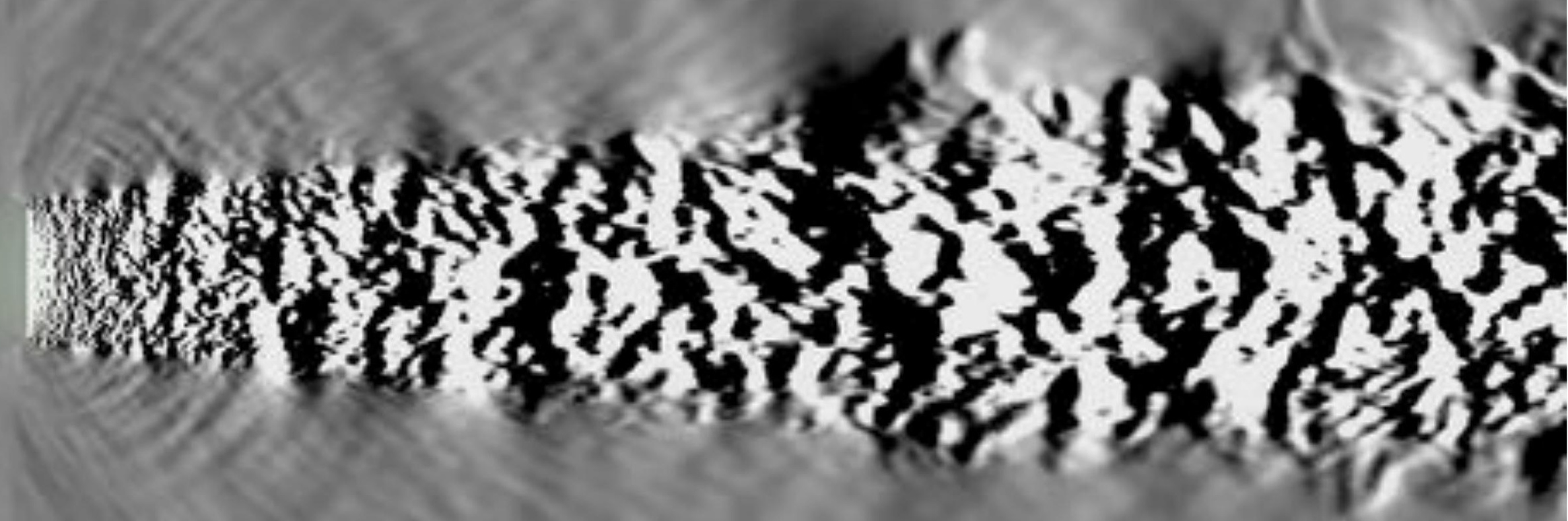




\section{Computational Results}

Flow Field Visualization: Iso-contours of Q-criteria colored by axial velocity

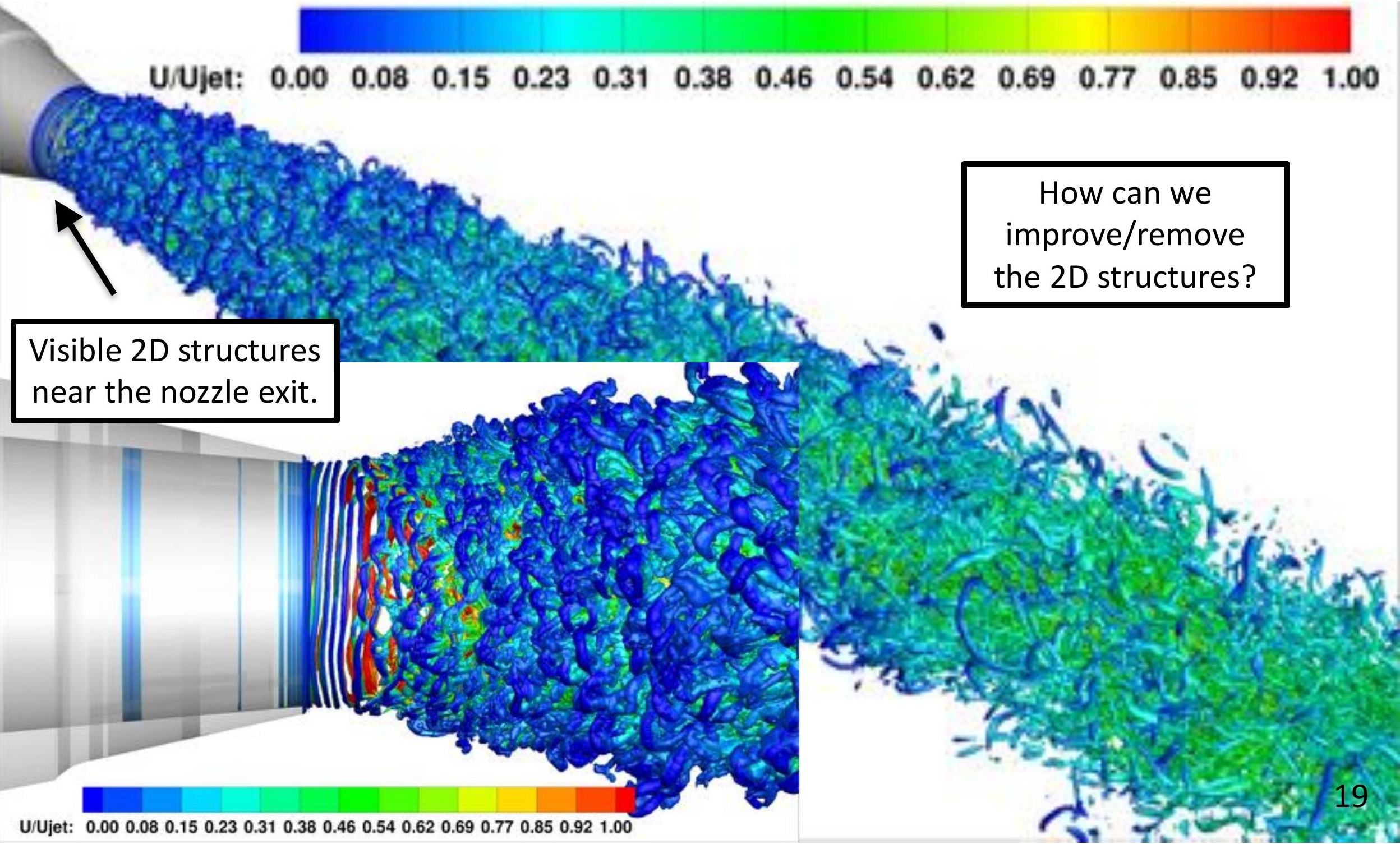




\section{Computational Results}

Indicator Function: DDES-256M

\section{$\mu_{T} / \mu_{\infty}:$ DDES-256M}

- Indicator function $f_{d}$ indicates RANS or LES mode.

- Stays in RANS mode in nozzle interior and quickly transitions to LES downstream of nozzle lip

- Retains large eddy viscosity throughout the boundary layer

- Shielding function RANS-NLES:

$$
f_{d}=1-\frac{1}{2}\left[1-\tanh \left(\epsilon_{d}\left(d_{\text {wall }}-d_{0}\right)\right)\right]
$$

$\mathrm{d}_{\text {wall }}$ : walldistance

$\mathrm{d}_{0} \quad$ : transition distance (user)

$\epsilon_{d} \quad$ : blending (user) 


\section{Computational Results}

Indicator Function: DDES-256M

$\mu_{T} / \mu_{\infty}:$ DDES-256M
Indicator Function: RANS-NLES-SEM-106M

$$
Y^{+} \approx 100
$$

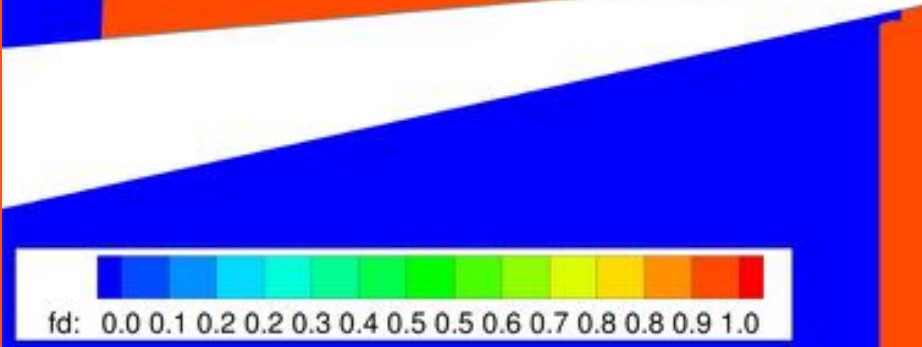

\section{$\mu_{T} / \mu_{\infty}:$ RANS-NLES-SEM-106M}

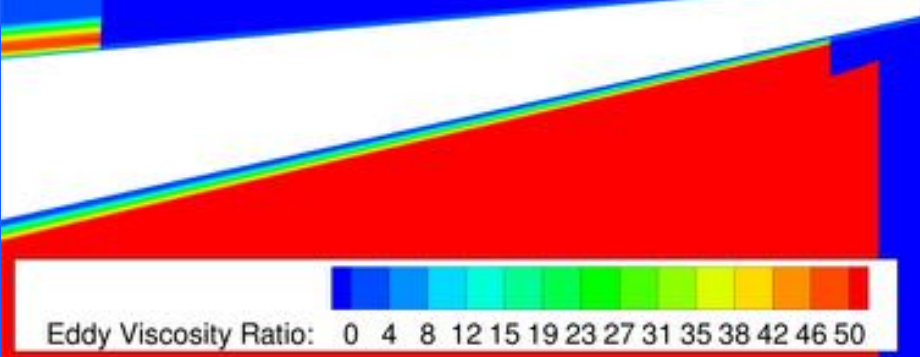




\section{Computational Results}

RANS-NLES-SEM Refined Mesh

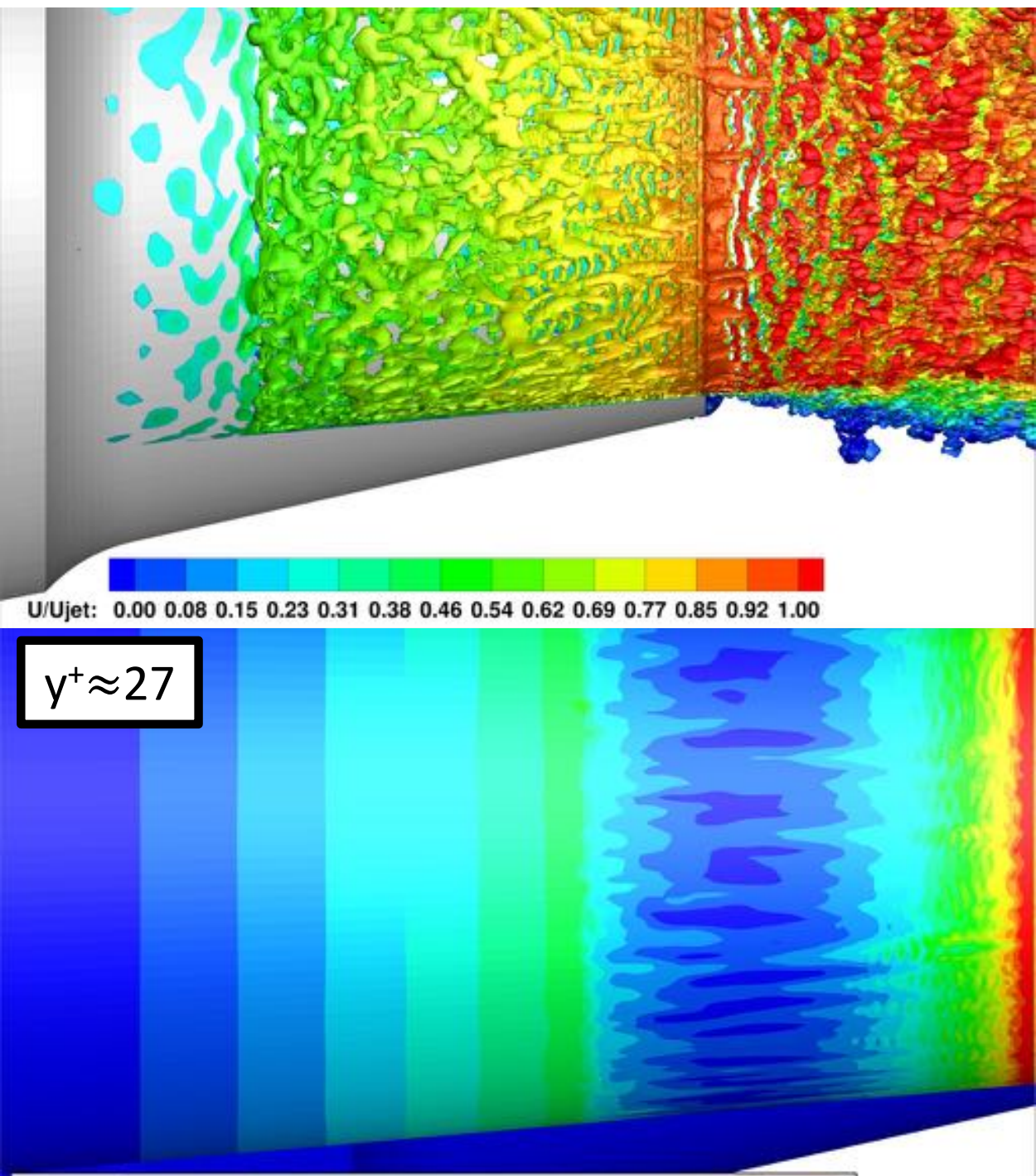

- Quasi-2D waffle cone structures at nozzle exit

- Size of turbulent structures appears to be too large inside nozzle

- Structures deep in the boundary layer show very little azimuthal variation

- Features are elongated and too highly correlated in both the streamwise and azimuthal direction

- Do we have realistic, fully developed BL turbulence at ${ }_{22}$ the exit? 


\section{Computational Results - Near-Field}

Near-Field Comparison

Lipline

Centerline

- Near field turbulent statistics computed from DDES, RANSNLES and RANS-NLES-SEM models for comparison with PIV data from the SHJAR

o Comparison of measurements to data at lipline $(z / R=1)$ and centerline $(\mathrm{z} / \mathrm{R}=0)$ 


\section{Near-Field: Time-Averaged Centerline}

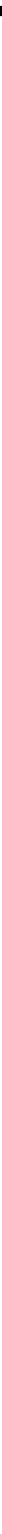




\section{Near-Field: RMS Centerline}

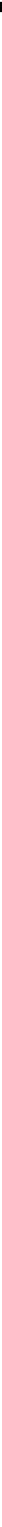




\section{Near-Field: RMS Lipline}

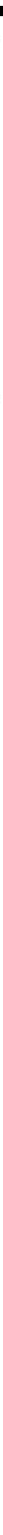




\section{Computational Results - Far-Field}

FWH Permeable Surface

Observers 100 D away

- Generated surface triangulation embedded within the overset grid

o FWH surface spans the entire axial domain of the computational grid

- Edge length of the triangles set to $5 \mathrm{~mm}$

the
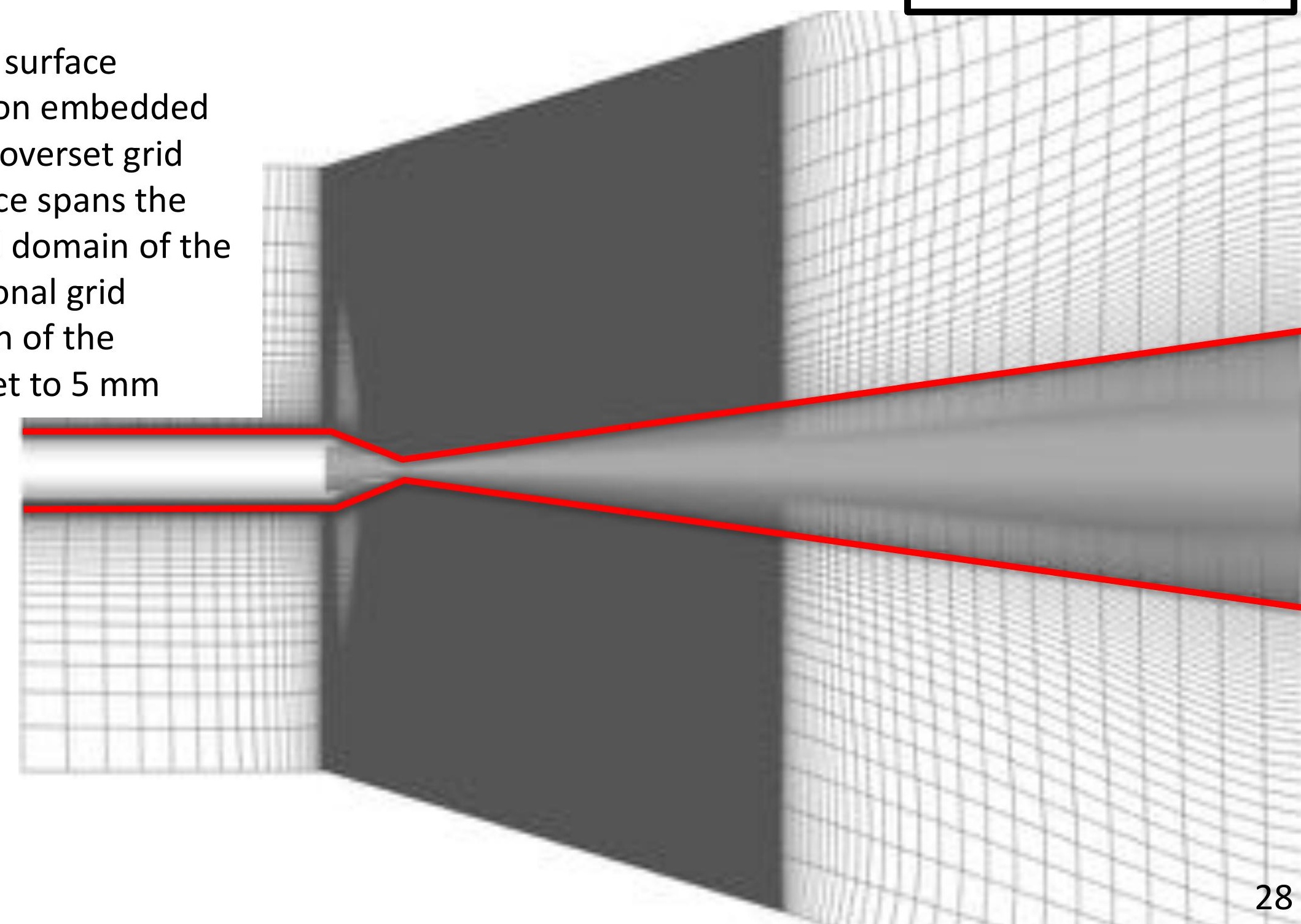


\section{Computational Results - Far-Field}

Observers $100 \mathrm{D}$ away

- Generated surface triangulation embedded within the overset grid

- FWH surface spans the entire axial domain of the computational grid

$\circ$ Edge length of the triangles set to $5 \mathrm{~mm}$

\section{rface

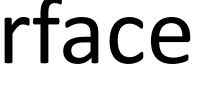

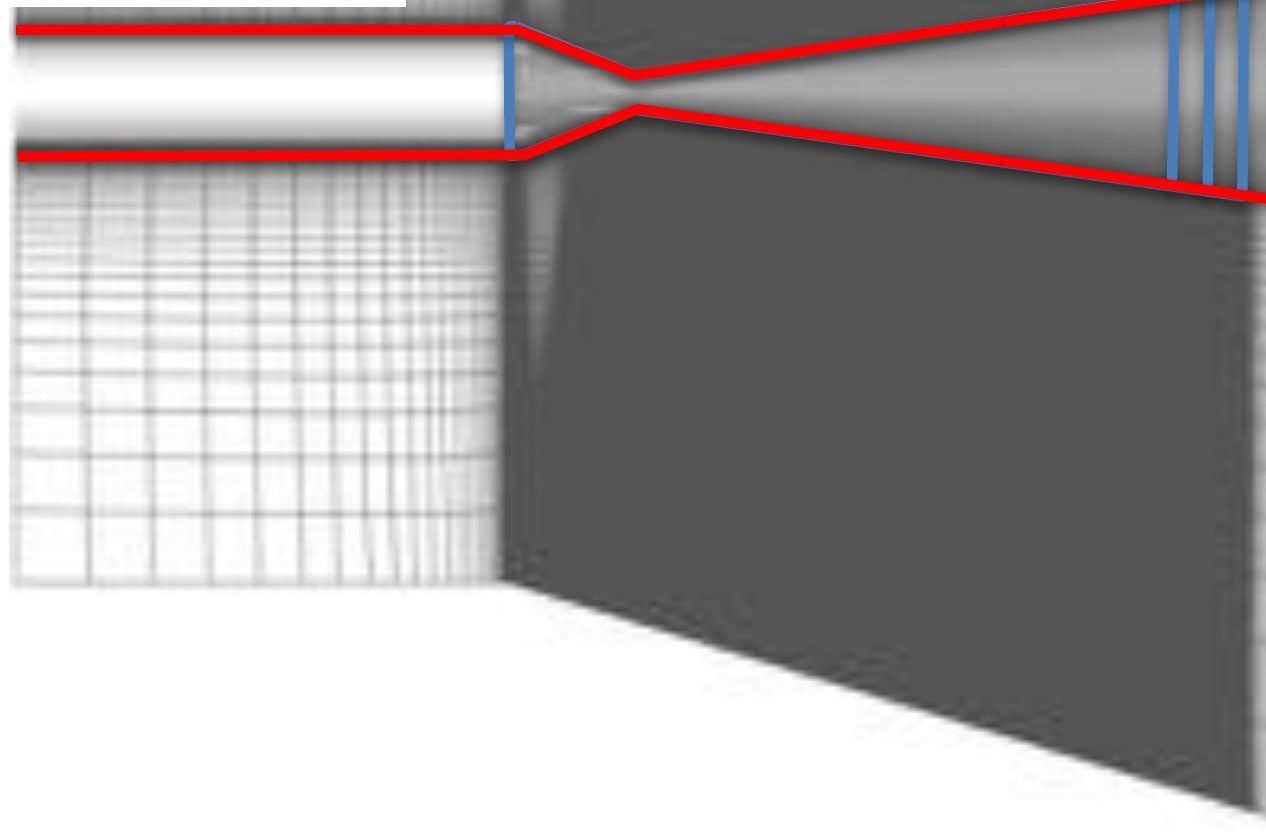




\section{Computational Results - Far-Field}

O Interpolate Volume solution to FWH surface at sampling rate of $\triangle \mathrm{t}=0.00001 \mathrm{~s}(100 \mathrm{kHz})$

o Split time sample into 5 windows (or segments) with $50 \%$ overlap at $\mathrm{St}_{\text {bin }}=0.02$

o Compute Integrands of $\mathrm{FWH}$ over each window independently

- $\mathrm{Q}_{n}, \mathrm{~F}_{1}, \mathrm{~F}_{2}, \mathrm{~F}_{3}$

- Hanning Window is applied in the time-domain

- FFT is applied and stored for computing far-field observer noise levels

o FWH surface integrals computed over each observer and window

- 360 observers, uniformly distributed along the azimuth, for each angle $\left(60^{\circ}, 90^{\circ}, 120^{\circ}, 150^{\circ}\right)$

- The PSD is ensemble averaged over the 360 observers

- PSD is multiplied by sqrt(8/3) to recover RMS levels lost from Hanning Window

o Finally, PSD spectrum is averaged over the 5 windows for final comparison to the experimental consensus. 


\section{Computational Results - Far-Field}
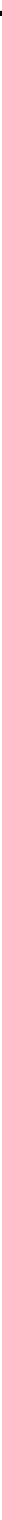

Far-Field Comparison: PSD Spectrum at 100D from exit 


\section{Computational Results - Far-Field}

Far-Field Comparison: Band-Limited OASPL $(0.08 \leq S t \leq 8.0)$

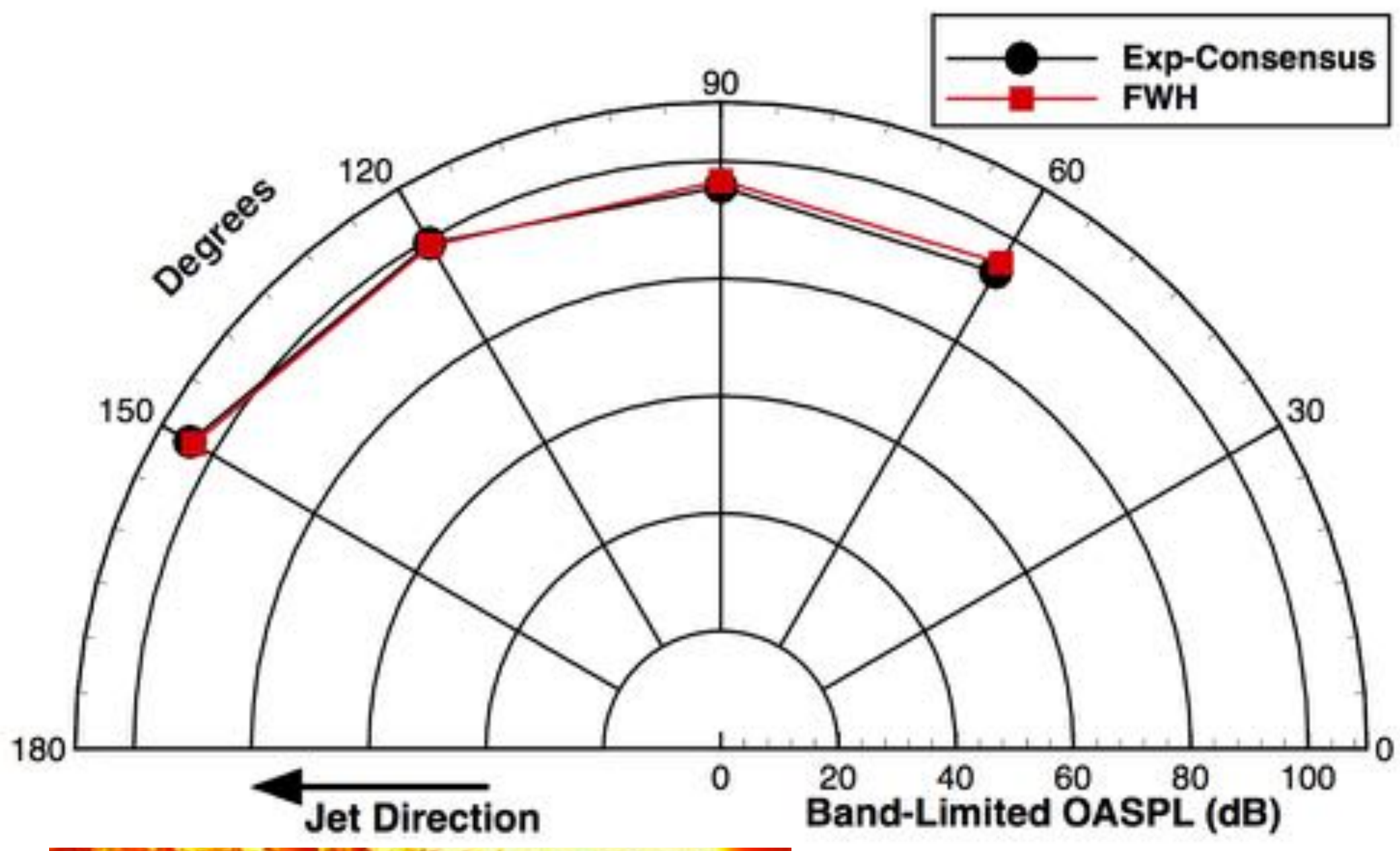




\section{Computational Results - Far-Field}

Far-Field Comparison: Band-Limited OASPL $(0.08 \leq S t \leq 8.0)$

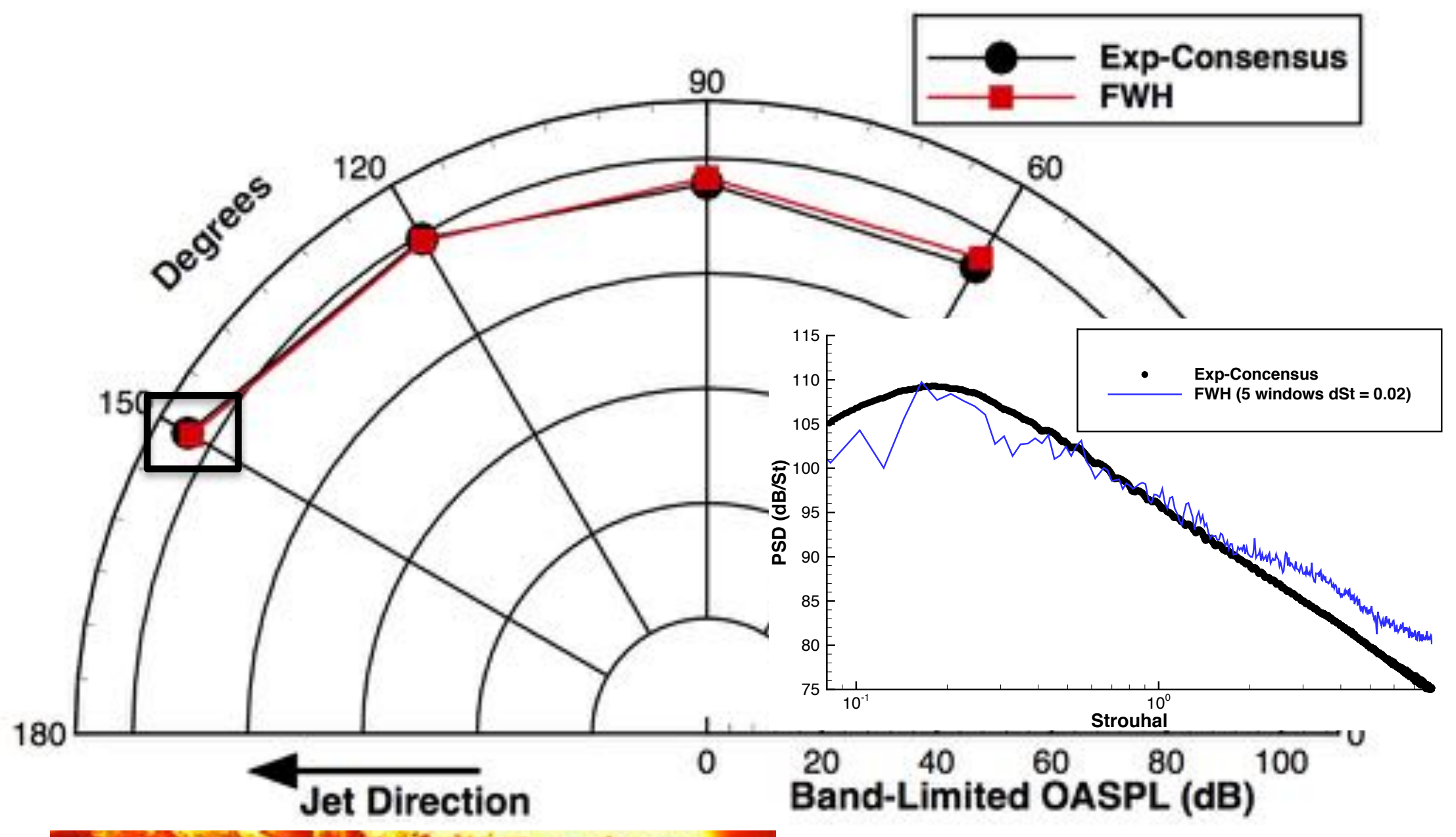




\section{Computational Results - Far-Field}

Time-Domain Pressure Associated with Peak Frequency $(1100 \mathrm{~Hz})$ in $150^{\circ}$
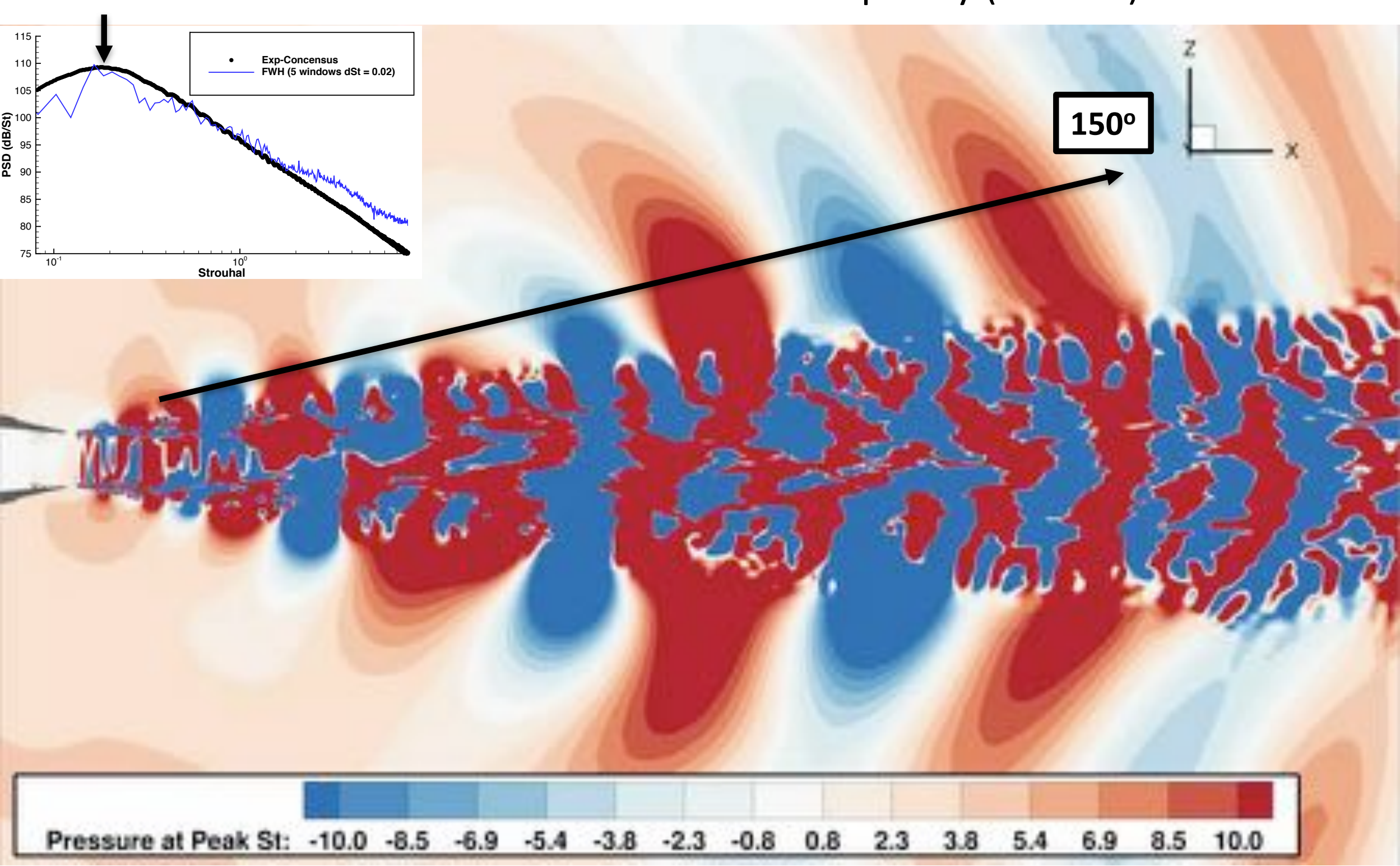


\section{Outline}

\section{- Introduction}

- Experimental Setup

- Computational Methodology

- Structured Overset Grid System

- Computed Results

- Near-Field Comparison

- Far-Field Comparison

o Summary

o Future Work 


\section{Summary}

O The hybrid RANS/LES approach, within the LAVA framework, using structured curvilinear overlapping grids for the prediction of jet noise and compared our results to existing near-field PIV and farfield microphone data.

O Demonstrated improvements:

- Hybrid RANS-NLES reduces the delay in transition to 3D turbulent structures and improved lip-line RMS prediction

- SEM eliminates delay even further

- Completed far-field acoustic propagation

- Mach wave radiation noise in the jet direction is well-captured

- $\quad$ Sideline noise caused by turbulent fluctuations is over-predicted, likely due to elevated lip-line RMS at nozzle exit

O BL needs to be resolved better inside of nozzle for further improvements 


\section{Future Work}

\section{LES with explicit subgrid-scale (SGS) model and SEM}

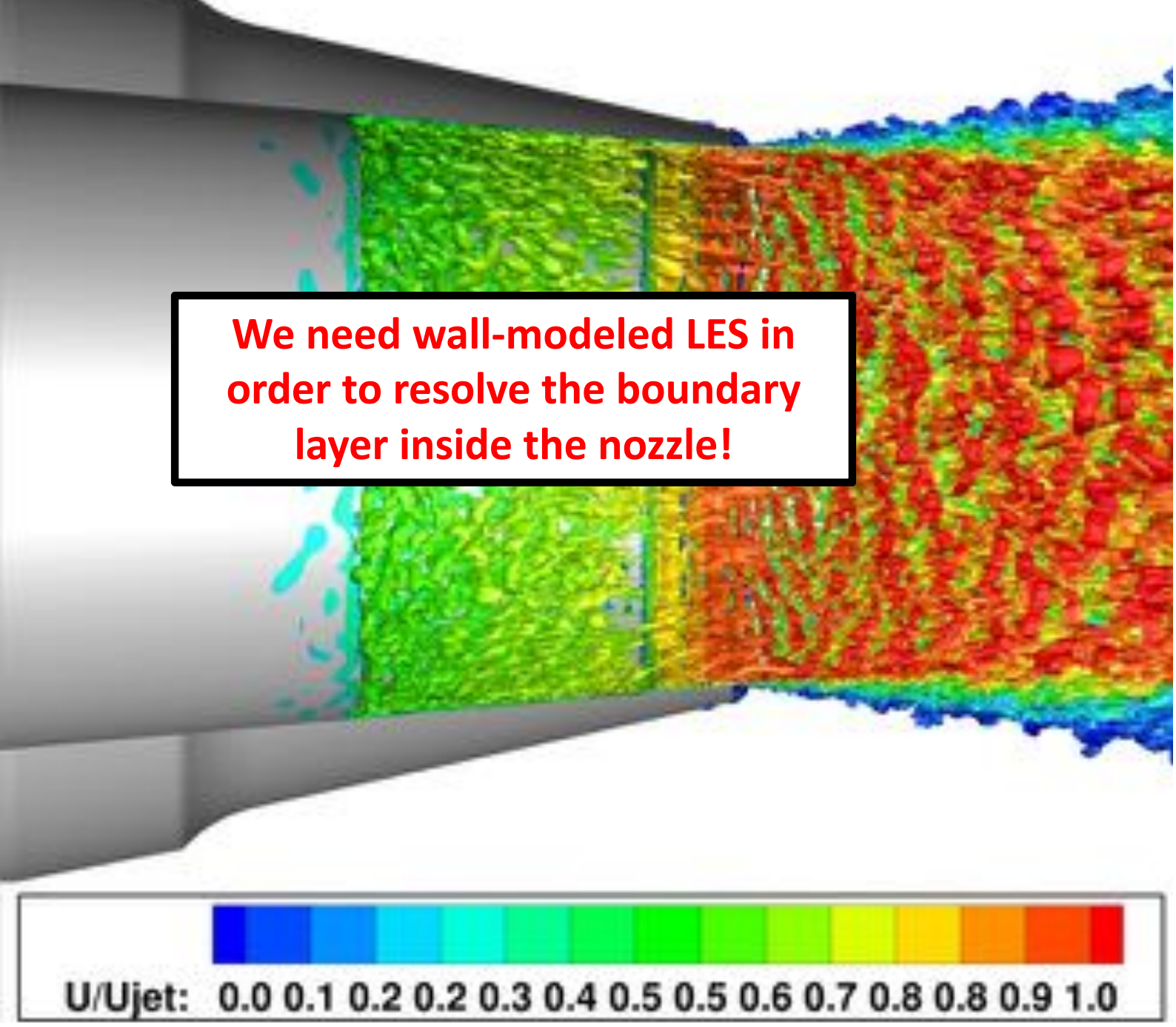

- No RANS downstream of SEM location

- Waffle cone structures inside nozzle reduced

- Artificial turbulence from SEM decays towards nozzle exit due to lack of resolution

- Recommended resolution: wall-resolved $\Delta s_{\text {circ }}^{+}=20$

(12.5k points) wall-modeled $\Delta s_{\text {circ }}=0.1 \delta$ (2450 points)

\section{QUESTION:}

"How will SGS model affect our lipline RMS and farfield solutions" 


\section{Acknowledgements}

O This work was also partially funded by the Commercial Supersonics Technology (CST) project and the Transformational Tools and Technology $\left(\mathrm{T}^{3}\right)$ project under the Aeronautics Research Mission Directorate (ARMD).

O Computer time has been provided by the NASA Advanced Supercomputing (NAS) facility at NASA Ames Research Center.

- Patrick J. Moran from NASA Ames visualization team for rendering of numerical schlieren video.

- Team members of LAVA group for helpful discussions and advise: Joseph George Kocheemoolayil, Francois Cadieux, Michael Barad 


\section{Questions?}

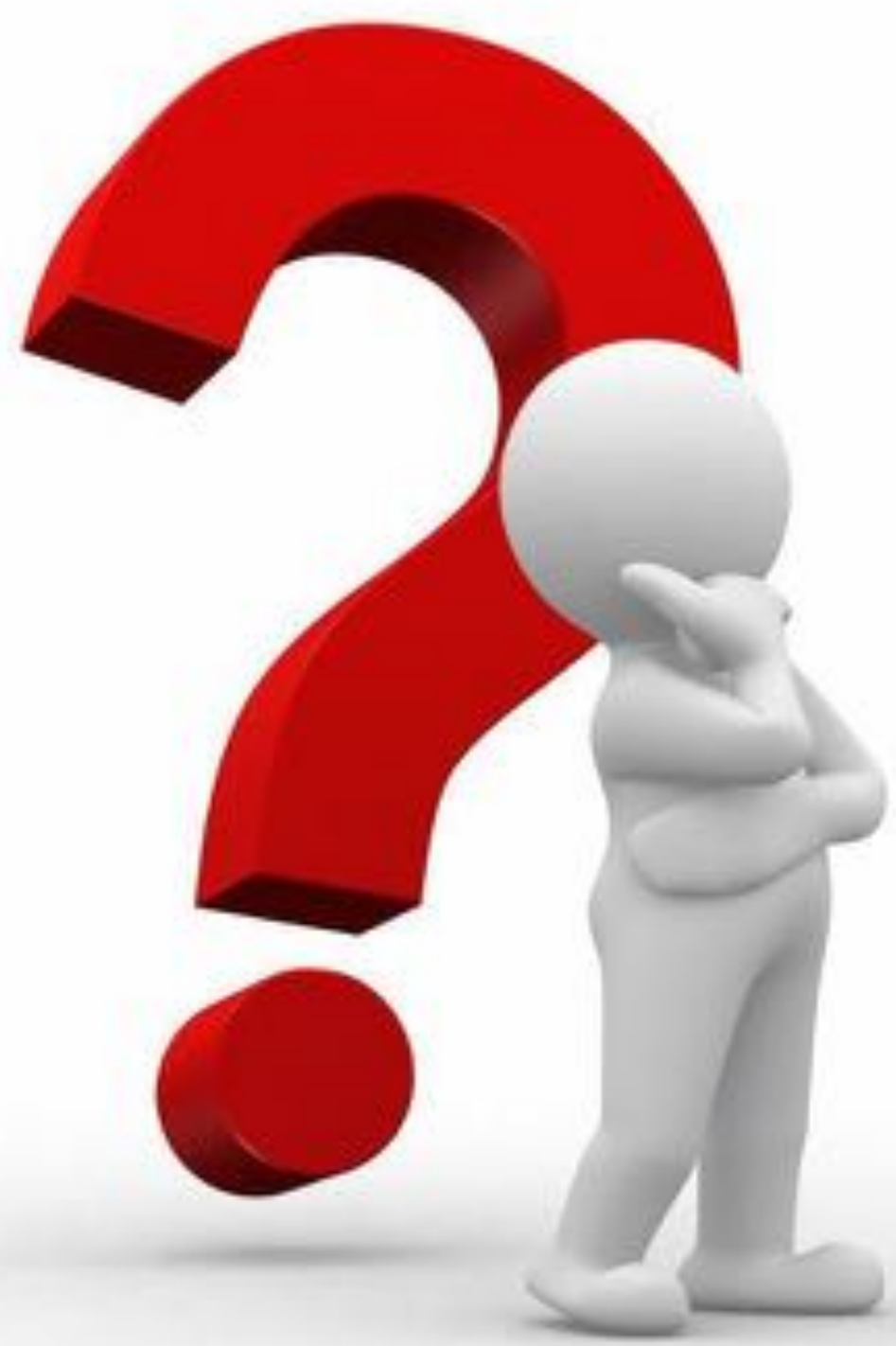




\section{Far-Field PSD}
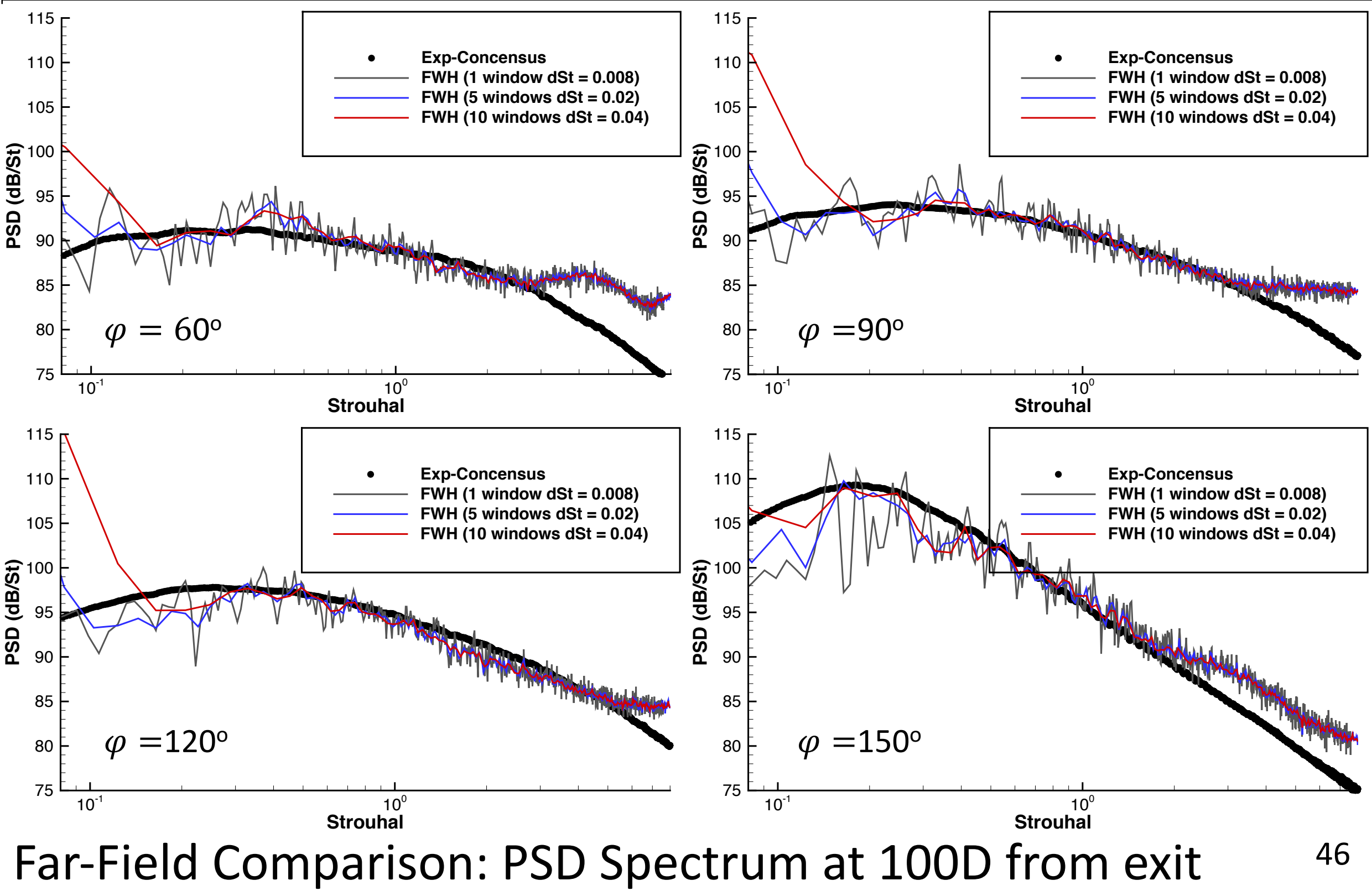

Far-Field Comparison: PSD Spectrum at 100D from exit 


\section{Hybrid RANS/LES}

\section{Non-Zonal model:}

- DES suffers from model stress depletion (forces transition to LES but mesh too coarse to resolve field)

O DDES remains in RANS mode in attached BL. Shielding function often shows strange behavior in transition (RANS -> LES -> RANS -> LES)

O Improved length scale (Shur, Spalart, Strelet): depletes eddy viscosity faster.

- Grey-Zone-Problem: mesh fine enough to trigger $3 \mathrm{~d}$ fluctuations in the $\mathrm{BL}$, but not fine enough to resolve largest scales in BL for accurate skin-friction.

\section{Zonal model:}

O User defines zones of RANS, LES and RANS/LES

O Numerical LES (NLES) includes wall distance and $\mathrm{y}^{+}$based transition

○ Grey-Zone-Problem is still an issue

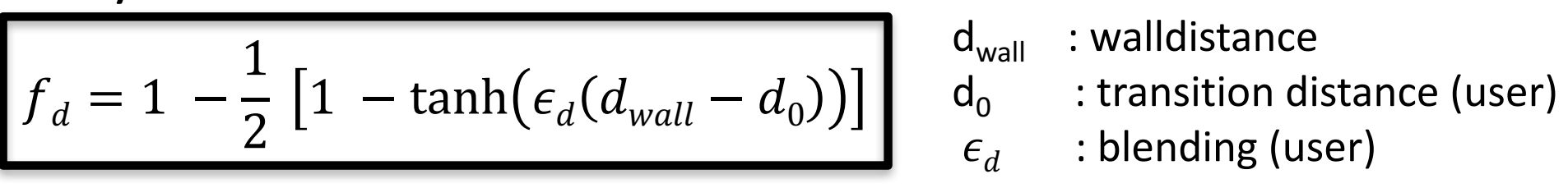




\section{Hybrid RANS/NLES}

$C_{1}=10$

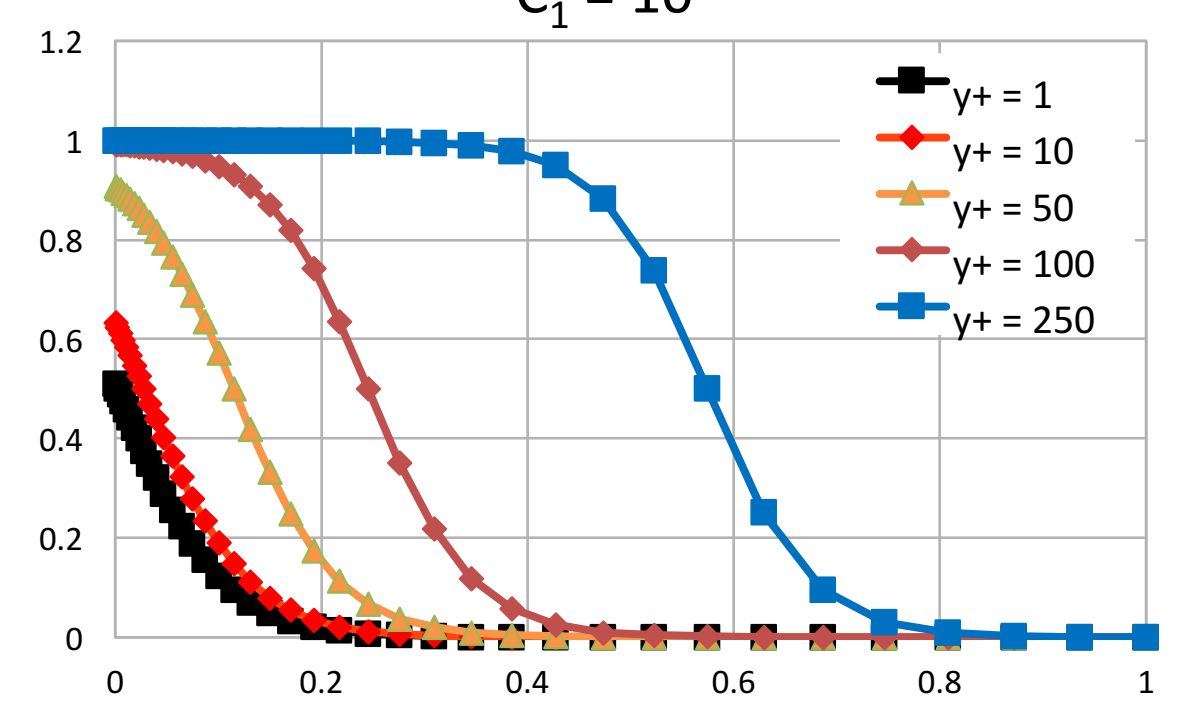

$[L E S / R A N S]=(1-\Gamma(\eta)) \cdot[L E S]+\Gamma(\eta) \cdot[R A N S]$

$\Gamma(\eta)=\frac{1}{2}-\frac{1}{2} \cdot \tanh \left[C_{1} \cdot\left(\eta-\eta_{0}\right)\right]$

$\eta$ distance from the wall

$\eta_{0}$ controlls where the blending starts

$\mathrm{C}_{1}$ controlls the blending "width"
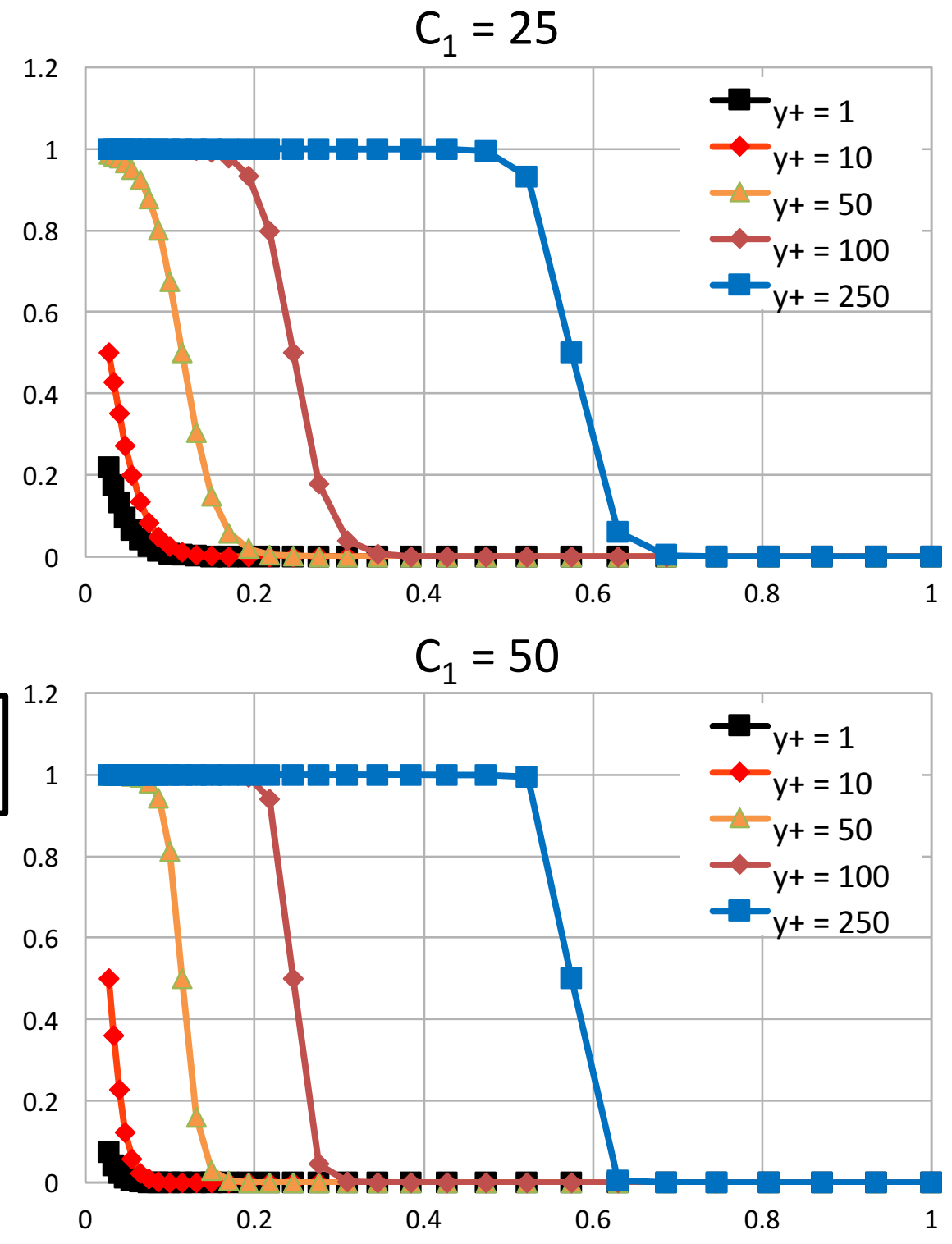


\section{Synthetic Eddy Method (SEM)}

Jarrin, N. (2006) - A Synthetic-eddy-method for generationg inflow conditions for LES

1. Define a Box of eddies with:

$$
x_{j, \min }=\min _{\mathbf{x} \in S}\left(x_{j}-\sigma_{i j}(\mathbf{x})\right) \quad x_{j, \max }=\max _{\mathbf{x} \in S}\left(x_{j}+\sigma_{i j}(\mathbf{x})\right)
$$

2. Generate for each eddy $k$ random vectors for the location $x^{k}$ and intensity $\varepsilon^{k}$

3. Compute the velocity signal on the set of Points $S$ with:

$$
\begin{aligned}
& u_{i}=U_{i}+\frac{1}{\sqrt{N}} \sum_{k=1}^{N} a_{i j} \epsilon^{k} f_{\sigma_{i j}}\left(x-x^{k}\right) \\
& f_{\sigma_{i j}}\left(x-x^{k}\right)=\sqrt{V_{b}} \cdot \frac{1}{\sigma_{i 1}} f\left(\frac{x_{1}-x_{1}^{k}}{\sigma_{i 1}}\right) \cdot \frac{1}{\sigma_{i 2}} f\left(\frac{x_{2}-x_{2}^{k}}{\sigma_{i 2}}\right) \cdot \frac{1}{\sigma_{i 3}} f\left(\frac{x_{3}-x_{3}^{k}}{\sigma_{i 3}}\right)
\end{aligned}
$$$$
f(x)= \begin{cases}\sqrt{\frac{3}{2}}(1-|x|) & x<1 \\ 0 & \text { else }\end{cases}
$$

4. Convect the eddies through $B$ with velocity $U_{\text {ref }}$

$$
x^{k}(t+d t)=x^{k}(t)+U_{\text {ref }} \cdot d t
$$

5. Generate new locations $x_{k}$ and intensities for eddies which were convected out of $B$. Advance to next time step and go back to step 3 


\section{Launch Ascend and Vehicle Aerodynamics (LAVA)}

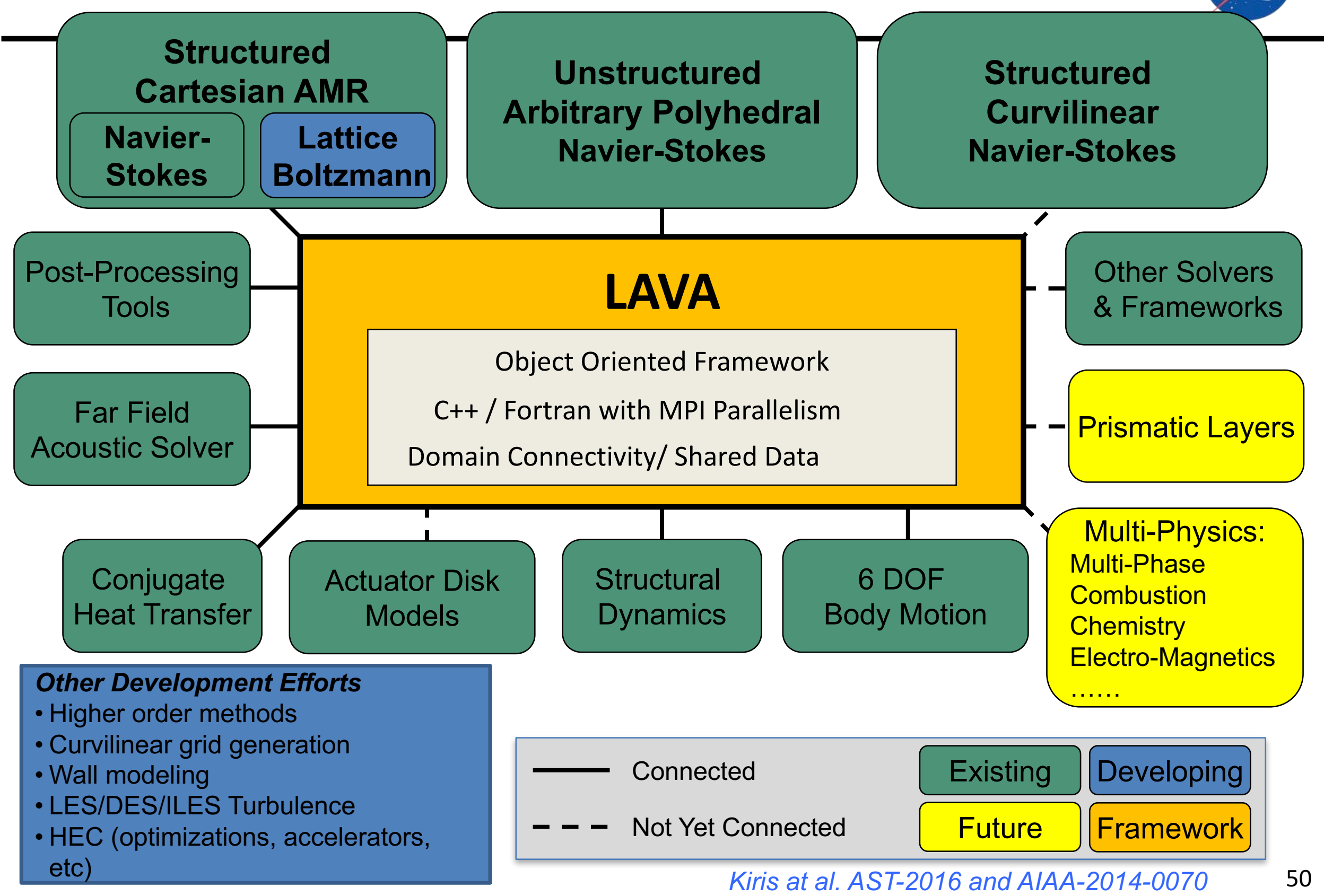

